\title{
Secondary Aroma: Influence of Wine Microorganisms in Their Aroma Profile
}

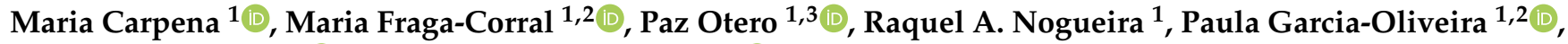 \\ Miguel A. Prieto $1,2, * \mathbb{D}$ and Jesus Simal-Gandara $1, * \mathbb{D}$
}

1 Nutrition and Bromatology Group, Analytical and Food Chemistry Department, Faculty of Food Science and Technology, University of Vigo, Ourense Campus, E-32004 Ourense, Spain; maria.carpena.rodriguez@uvigo.es (M.C.); mfraga@uvigo.es (M.F.-C.); pazoterofuertes@gmail.com (P.O.); raquelnogueira36@gmail.com (R.A.N.); paula.garcia.oliveira@uvigo.es (P.G.-O.)

2 Centro de Investigação de Montanha (CIMO), Instituto Politécnico de Bragança, Campus de Santa Apolonia, 5300-253 Bragança, Portugal

3 Department of Pharmacology, Pharmacy and Pharmaceutical Technology, Faculty of Veterinary, University of Santiago of Compostela, 27002 Lugo, Spain

* Correspondence: mprieto@ipb.pt (M.A.P.); jsimal@uvigo.es (J.S.-G.)

check for updates

Citation: Carpena, M.; Fraga-Corral, M.; Otero, P.; Nogueira, R.A.; Garcia-Oliveira, P.; Prieto, M.A.; Simal-Gandara, J. Secondary Aroma: Influence of Wine Microorganisms in Their Aroma Profile. Foods 2021, 10, 51. https://dx.doi.org/10.3390/ foods10010051

Received: 29 November 2020 Accepted: 23 December 2020 Published: 27 December 2020

Publisher's Note: MDPI stays neutral with regard to jurisdictional claims in published maps and institutional affiliations.

Copyright: (C) 2020 by the authors. Licensee MDPI, Basel, Switzerland. This article is an open access article distributed under the terms and conditions of the Creative Commons Attribution (CC BY) license (https: / / creativecommons.org/ licenses/by/4.0/).

\begin{abstract}
Aroma profile is one of the main features for the acceptance of wine. Yeasts and bacteria are the responsible organisms to carry out both, alcoholic and malolactic fermentation. Alcoholic fermentation is in turn, responsible for transforming grape juice into wine and providing secondary aromas. Secondary aroma can be influenced by different factors; however, the influence of the microorganisms is one of the main agents affecting final wine aroma profile. Saccharomyces cerevisiae has historically been the most used yeast for winemaking process for its specific characteristics: high fermentative metabolism and kinetics, low acetic acid production, resistance to high levels of sugar, ethanol, sulfur dioxide and also, the production of pleasant aromatic compounds. Nevertheless, in the last years, the use of non-saccharomyces yeasts has been progressively growing according to their capacity to enhance aroma complexity and interact with S. cerevisiae, especially in mixed cultures. Hence, this review article is aimed at associating the main secondary aroma compounds present in wine with the microorganisms involved in the spontaneous and guided fermentations, as well as an approach to the strain variability of species, the genetic modifications that can occur and their relevance to wine aroma construction.
\end{abstract}

Keywords: wine secondary aroma; fermentation; non-saccharomyces yeasts; lactic acid bacteria; volatile compounds; strain variability

\section{Introduction \\ 1.1. Secondary Wine Aroma}

The combination of two modest substrates such as grapes and microorganisms (those belonging to the grape microbiota and/or those intentionally added) results in a huge variability and diversity of wines. However, this apparently simple conjugation hinders extremely specific chemical reactions that can be modified to obtain a stunning array of aromas and flavors. The wine aroma comprises a mixture of volatiles that can account up to 800 compounds, although just few of them are odor-active [1]. This complex chemical composition can be split in terms of aromas into three different categories that are mostly related with the three production steps: grape culture, fermentation stage and transformation process, respectively [2].

Primary or varietal aromas, as this second name indicates, are due to the grape variety. Primary aromas belonging to the same grape variety may present different features depending on natural factors derived from weather, type of soil, fertilization, presence/absence of plagues or even the geographical location, that prompt different cultivation conditions in 
each area and also each year. Besides, the ripening period and the care of the collector when selecting grapes may have influence in the final primary aroma of wine [1]. Grapes are known to contain free and sugar-glycosidically-linked terpenes, being the monoterpenes and sesquiterpenes the ones that contribute with aroma and flavor. Among them, the most odoriferous monoterpenes alcohols are linalool, geraniol, nerol, citronellol, 3,6-dimethyl1,5-octa-dien-1,7-diol, hotrienol and $\alpha$-terpineol, which provide floral, fruity and citrus aroma to the wine [3,4]. Even though just few aromas have been directly associated to specific varieties, each grape variety possesses an aroma fingerprint. Monoterpene glycosides or ethers do not show significant changes in their amount during yeast fermentations. Therefore, they can be used to classify different varieties, such as Muscat and Riesling wines, by the study of their analytical composition based on just 12 monoterpene compounds [5-7]. However, the low concentration of these aromas (e.g., hotrienol thresholds between 18 and $400 \mu \mathrm{g} / \mathrm{L}$ and linalool in $50 \mu \mathrm{g} / \mathrm{L}$ ) does not permit their sensorial appreciation at least their potential gets boosted in later steps by enzymatic reactions thus, having a major impact in the final wine aroma [8,9]. Wine has been demonstrated to have more than 800 volatile compounds with wide range of concentration, from ng/L to hundreds of $\mathrm{mg} / \mathrm{L}$ [10]. In addition, other precursors that do not possess odoriferous characteristics, are involved in the development of other aroma substances (e.g., monoterpenes, diols or terpene, polyols, fatty acids, carotenoids, glycosylated precursors of aroma and volatile phenols) [1].

In the next aromatic level, yeasts and bacteria carry out the fermentation, this is the chemical reactions chain responsible for transforming grape juice into wine and providing secondary aromas to wine. Secondary aromas can be divided into pre-fermentative, those arisen due to the mechanical treatment of grapes, and fermentative, those boosted during alcoholic or malolactic fermentation processes [1,2]. The most utilized species for the alcoholic fermentation is Saccharomyces cerevisiae, although there are about 20 yeast genera with the same capacity such as Saccharomycodes, Candida, Issatchenkia, Pichia, Hanseniaspora (Kloeckera) or Brettanomyces (Dekkera) [3]. These non-saccharomyces species drive the aroma release by the secretion of proteins, mainly enzymes, and the synthesis of new secondary metabolites. In addition, they contribute to color wine stability and they do not use up the available sugar in must. Thus, they are strategically utilized for creating multi-starter, mixed or sequential cultures in combination with S. cerevisiae $[8,11,12]$. Normally, after the alcoholic fermentation, wine is submitted to the malolactic fermentation by the inoculation of lactic acid bacteria (LAB). During this stage, malic acid responsible for the tart taste gets decarboxylated by the action of Oenococcus oeni or Lactobacillus plantarum, two common used LAB species [8]. After this fermentation process, wine is microbiologically stabilized. Along the fermentation, the main created aromas belong to the volatile fatty acids, higher alcohols, acetate and ethyl ester categories which make evolve the aroma profile of wine [3]. These molecules are usually present at high sensory thresholds (the oxidation products of linalool possesses a perception threshold of $6000 \mu \mathrm{g} / \mathrm{L}$ ) and their combination creates the matrix of wine aroma $[3,13]$. In fact, by the end of this fermentative stage, the term aroma becomes more complex from a chemical and sensorial point of view and thus, it turns into the term bouquet. Therefore, even though the final wine aroma composition is highly dependent on fermentative species and strains, the grape microbiome is gaining attention, since different works point to its relevance in the final sensorial properties of wines $[8,12]$.

Tertiary aromas are created during the last step, aging of wine, where the storage of the final product is the main responsible for the transference of aromas and flavors to wine. The typical aging method is the use of wood barrels mostly built with different oak species such as Quercus alba, Q. robur or Q. petraea [14]. Wine aged in these barrels may be transferred with volatiles such as guaiacol-oak lactones or vanillin and even with furfural, 5-methylfurfural, eugenol, guaiacol, 5-hydroxymethylfurfural, 4-methylguaiacol, guaiacol and syringol, when applying different toast treatments to wood [15]. The use of different wood provides different volatiles to aged wine, for instance, brandies aged in 
Quercus-barrels were found to contain higher levels of ethyl-2-methylpropanoate, -butyrate and -octanoate and lower levels of butanoic acid, cis- $\beta$-methyl- $\gamma$-octalactone and syringol than when aged in Castanea-barrels [15]. In fact, apart from Quercus, other kind of woods such as Acacia, Prunus or Castanea are known to contain high concentrations of tannins, a kind of polyphenols, that are utilized to age wines since these non-volatile molecules can be transferred and may contribute to sensory properties such as color, astringency and bitterness [2,16].

Among the three classes of aroma, achieving an appropriate combination of secondary aromas represents the most intricate procedure. This stage implies the correct selection of yeasts and bacteria to perform the fermentation steps while avoiding wine spoiling due to cross contamination or due to the innate grape microbiota. Moreover, the high sensory threshold of the volatiles synthesized during this stage will define the wine aroma matrix. For obtaining a wine with well-defined secondary aromas and flavors, it is essential to understand how different microbial species interact with each other and which sensorial properties are capable to provide based on the metabolic pathways they develop.

\subsection{Fermentation Implication on Wine Secondary Aroma}

As aforementioned, yeasts and bacteria are responsible for the production of the secondary aroma during the pre-fermentative and fermentation processes. Naturally, in traditional winemaking, fermentation of grape juice is carried out by different yeast species following an order. The fermentation is initialized by non-saccharomyces yeasts, which is called spontaneous fermentation. However, these yeasts do not resist the increase of ethanol and so, they are commonly replaced by the strongly winery fermentative yeast Saccharomyces cerevisiae [17]. Nevertheless, it has been suggested that some of the nonsaccharomyces species could persist from one year to another in wine and become dominant during fermentation like S. cerevisiae [18]. In the past, non-saccharomyces wine yeasts were considered as undesired microorganisms but in recent years it is well known that they can enhance the analytical composition and aroma profile of wine [19]. Therefore, wine fermentation can be defined as a complex process where different microorganisms coexist and microbial interactions influence the final product [20]. Non-saccharomyces yeasts can influence both the primary and secondary aroma through the production of enzymes and metabolites, respectively [19]. In this context, and for the development of the following sections, it is important to differentiate between the three types of alcoholic fermentations that can occur. Besides, malolactic fermentation is a process that some type of wines can also undergo (i.e., wines with high acidity) and consequently, causes an improvement of the aromatic profile of wines [5]. This process will be explained in the following sections.

Firstly, spontaneous fermentation is a process that naturally takes place on grape must: at the initial stages, non-saccharomyces species (already present in grapes) dominate grape juice and are then replaced by winery yeasts, commonly $S$. cerevisiae, leading to wines with a complex profile but with lower microbiological control and submitted to variability and the risk of spoilage depending on the year and the exogenous microbiota of the grapes [19]. Next, the second type of fermentation is called guided, since wine is inoculated with selected cultures named as starters which compete and limit the growth of non-saccharomyces strains [21]. This way, industrial fermentations begun to use starters of selected wine yeast strains of $S$. cerevisiae for their fermentative behaviour, their ability to enhance secondary aroma but also to achieve more uniformity in the quality of wines [19]. However, it is currently accepted that those fermentations that use more than one yeast strain can produce wine with higher quality and complexity and less content in alcohol, while microbiological control is ensured. These are called mixed fermentations [20]. Mixed cultures have shown to exert additive or synergistic effect (e.g., by metabolites exchange between yeasts) resulting in the enhancement of the chemical and sensory profile of wines $[22,23]$. A representation of the types of fermentations is shown in Figure 1. 


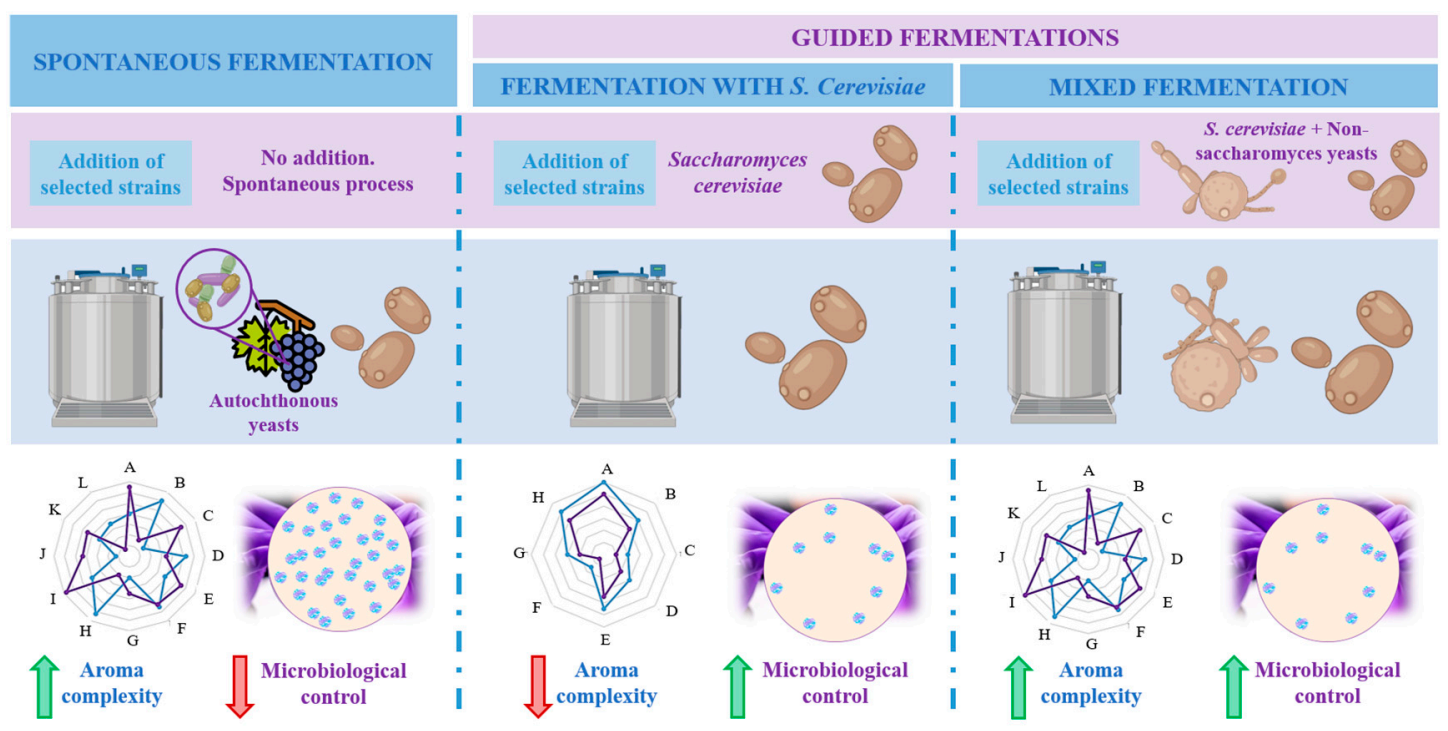

Figure 1. Schematic representation of the types of fermentation, the implied yeasts and the final characteristics of the obtained wine according to aroma complexity and microbiological control. Based on Reference [19].

It has been also highlighted that the selected inoculation strategy can modulate wine aroma profile in the case of mixed fermentations. If simultaneous inoculation is chosen, nonsaccharomyces yeast and S. cerevisiae are added together, whereas in the case of sequential inoculation, non-saccharomyces starter is inoculated before S. cerevisiae, thus delaying the development of this last one [24,25]. In this sense, both strategies have shown aroma improvements depending on the utilized species. For instance, the aroma compounds resulting from the sequential fermentation of Issatchenkia terricola and Pichia kudriavzevii together with S. cerevisiae where higher than in the case of simultaneous fermentation [24]. In the other hand, a different experiment carried out with Torulaspora delbrueckii and S. cerevisiae showed an increase in the production of esters (fruity aroma) in the case of simultaneous fermentation when compared to sequential fermentation [26].

At last, it is worth to mention that other parameters during fermentation can also influence the wine aroma. These are temperature, molecular oxygen available during fermentation, maturation or ageing, the nitrogen source also known as yeast assimilable nitrogen (YAN) and the inoculation rate of yeasts as well as other post-fermentative parameters, such as yeasts final autolysis [27].

\subsection{Microorganisms Implied in Wine Aroma}

Wine is a complex matrix where the development of alcoholic fermentation, leaded by different yeasts coupled to the volatile compounds released during malolactic fermentation, leaded by LAB and acetic acid bacteria (AAB), defines wine secondary aroma [8]. Yeasts are responsible for alcoholic fermentation, and particularly, the unicellular fungi Saccharomyces cerevisiae governs the process, which can occur spontaneously or guided by the use of starter cultures [17]. Yeast domain counts up to more than 2000 species, among which Saccharomyces has traditionally been the most studied and important genus for industrial fermentation [8]. Within Saccharomyces species, S. cerevisiae is the most known since the first inoculation processes with a pure yeast culture were carried out with this species. This trend continued for many decades and resulted in the generalized use of S. cerevisiae as starter yeasts inmost wine fermentations [28]. However, as aforementioned, non-saccharomyces species also play an important role during fermentation. Among this group, the genera most commonly present and studied are Hanseniaspora, Hansenula, Metschnikowia, Candida, Pichia, Lachancea, Brettanomyces, Kluyveromyces, Schizosaccharomyces, Torulaspora, Zygosaccharomyces and Saccharomycodes [5,8]. In respect of bacteria, most abundant LAB belongs to genera Lactobacillus, Oenococcus, Pediococcus and Leuconostoc 
whereas most predominant $\mathrm{AAB}$ during winemaking are Acetobacter, Gluconobacter or Gluconacetobacter [29]. Figure 2 represents the main groups and taxonomy of the microorganisms implied in wine aroma. The challenge of winemakers and researches lies on the detection, characterization and quantification of all these microorganisms populations during fermentation to assess their participation on the development of wine secondary aroma [29].

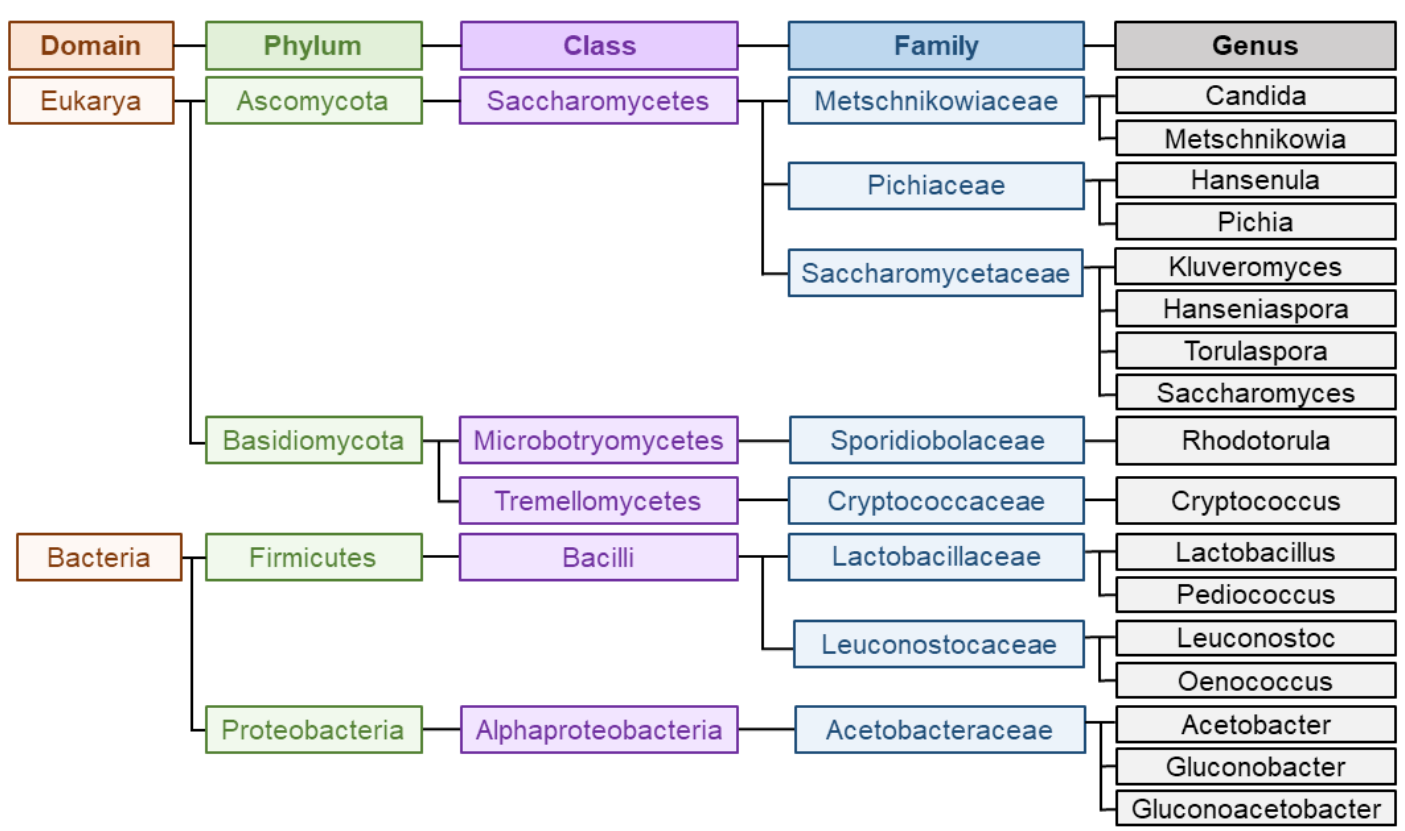

Figure 2. Main groups and taxonomy of the microorganisms implied in wine aroma production. Information extracted from Reference [30].

Therefore, this review presents an overview of the main secondary aromas present in wine, the microorganisms involved in the spontaneous and guided (simultaneous or mixed) fermentations as well as an approach to the aroma variation that wine can suffer when different strains and genetic modifications have occurred.

\section{Compounds Involved in Secondary or Fermentative Aroma}

The quality of wine is derived from its aroma which is, in turn, characterized by its volatile composition, mainly created during the fermentation stages. Fermentation is highly dependent on the species and strains selected but also on the components of the wine matrix. Among the main volatiles that define wine, higher alcohols, esters and fatty acids play a key role in the creation of secondary aromas (Table 1 and Figure 3).

\subsection{Volatile Fatty Acids}

In the category of aliphatic fatty acids, apart from the most abundant volatile acid, i.e., the acetic acid, the major medium chain fatty acids are hexanoic, octanoic or decanoic. Besides, in the group of the unsaturated fatty acids is worthy to mention 9-decenoic acid which possesses preservative properties and is relevant from an aroma point of view when transformed into ethyl ester [31]. 
Table 1. Compounds involved in secondary aroma, classes of volatile aroma, main representative, desirable concentration, sensorial properties and producer microorganisms.

\begin{tabular}{|c|c|c|c|c|c|}
\hline Aromatic Class & Main Compounds & $\begin{array}{c}\text { Desirable } \\
\text { Concentration }\end{array}$ & $\begin{array}{l}\text { Sensorial } \\
\text { Properties }\end{array}$ & $\begin{array}{l}\text { Producer } \\
\text { Organism }\end{array}$ & Ref. \\
\hline Fatty acids & $\begin{array}{l}\text { Acetic acid, pentanoic } \\
\text { acid, hexanoic acid, } \\
\text { octanoic acid, decanoic } \\
\text { acid, 9-Decenoic acid, } \\
\text { 3-methylbutanoic acid, } \\
\text { sobutyric acid }\end{array}$ & $200-700 \mathrm{mg} / \mathrm{L}$ & $\begin{array}{c}\text { In excessive } \\
\text { amount: rancid, } \\
\text { greasy, and cheesy } \\
\text { notes }\end{array}$ & $\begin{array}{l}\text { S. cerevisiae, } \\
\text { P. fermentas, } \\
\text { C. zemplinina, } \\
\text { H. guilliermondii, } \\
\text { H. vineae, } \\
\text { H. uvarum }\end{array}$ & {$[3,19,31]$} \\
\hline Higher alcohols & $\begin{array}{l}\text { 1-Propanol-isobutanol, } \\
\text { isoamyl alcohol, } \\
\text { 2-Phenylethanol, tyrosol, } \\
\text { tryptophol, } \\
\text { 2-methylbutanol-1, } \\
\text { 3-methyl-1-butanol-1 }\end{array}$ & $<300 \mathrm{mg} / \mathrm{L}$ & $\begin{array}{l}\text { Floral, honey, and } \\
\text { fruity notes } \\
(<300 \mathrm{mg} / \mathrm{L}) \\
\text { Pungent aroma } \\
\text { (>400 mg/L) }\end{array}$ & $\begin{array}{c}\text { S. cerevisiae, } \\
\text { C. zemplinin, } \\
\text { H. uvarum, } \\
\text { H. osmophila, } \\
\text { H. guilliermondii, } \\
\text { P. anomala, } \\
\text { P. membranifaciens }\end{array}$ & {$[2,3,5,8,19]$} \\
\hline Esters & $\begin{array}{l}\text { Ethyl hexanoate, ethyl } \\
\text { octanoate, ethyl } \\
\text { decanoate, ethyl acetate, } \\
\text { isobutyl acetate, amyl } \\
\text { acetate, hexyl acetate, } \\
\text { 2PA, isoamyl acetate }\end{array}$ & 150-200 mg/L & $\begin{array}{l}\text { Fruity aroma, } \\
\text { including banana } \\
\text { or apple, honey, } \\
\text { and floral tones }\end{array}$ & $\begin{array}{c}\text { S. cerevisiae, } \\
\text { Candida, Hansenula, } \\
\text { Pichia }\end{array}$ & {$[2,3,7,19]$} \\
\hline Phenolics & $\begin{array}{l}\text { 4-Vinyl guajacol, } \\
\text { 4-Vinylphenol }\end{array}$ & - & $\begin{array}{l}\text { Sweet vanillin } \\
\text { aroma }\end{array}$ & LAB & {$[1,7,31]$} \\
\hline
\end{tabular}

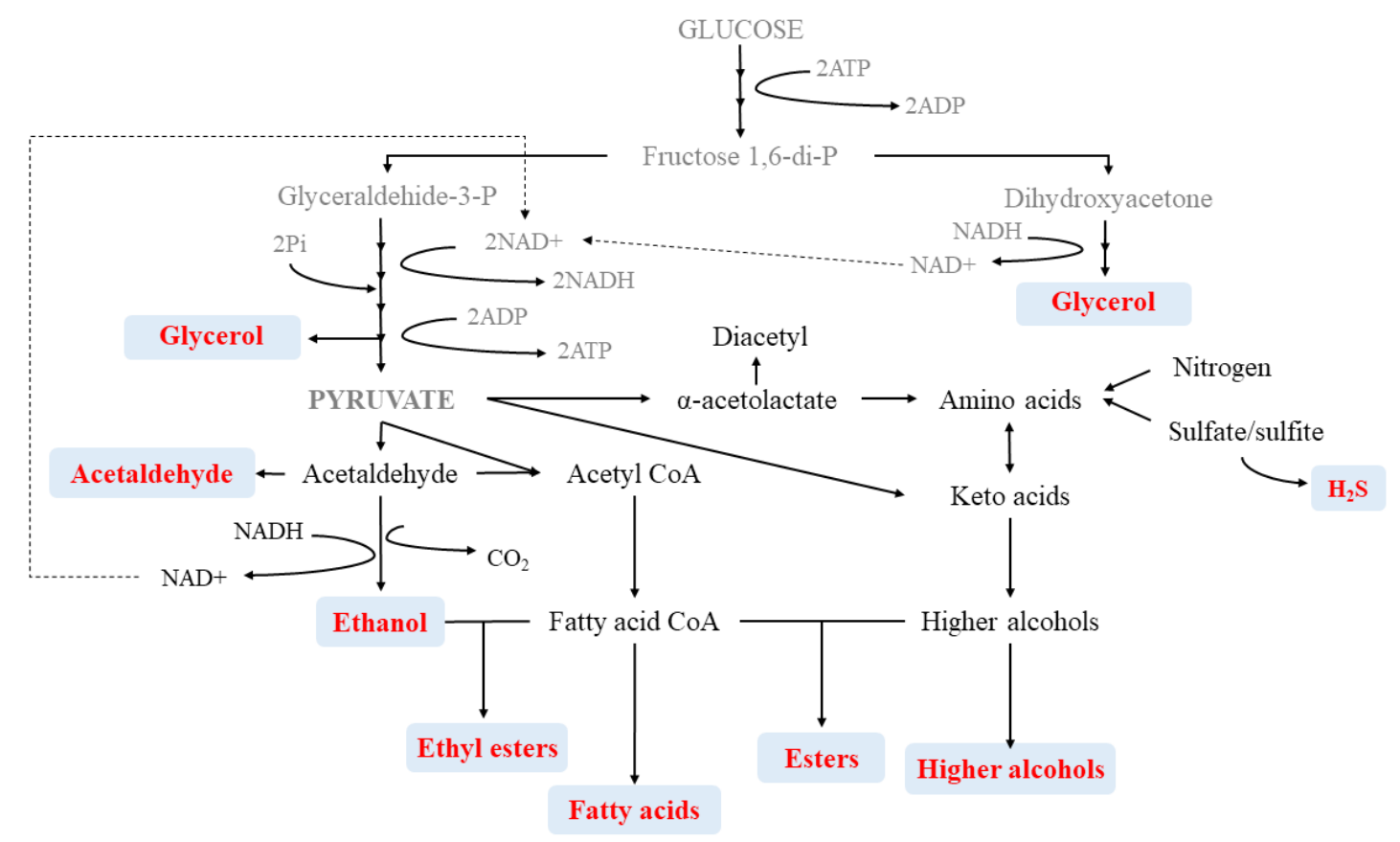

Figure 3. General representation of aroma compound metabolism.

Yeasts are the primary producers of these fatty acids which are the initial substrate for the final formation of ethyl esters. Among yeasts, S. cerevisiae is capable of synthesizing mainly hexanoic and octanoic acids in high amounts, but also pentanoic, decanoic and 3-methylbutanoic acids. Other non-saccharomyces species such as the genus Hanseniaspora has been described to produce acetic acid (in very variable ranges, from 0.6 up to $3.4 \mathrm{~g} / \mathrm{L}$ ) and species such as Hanseniaspora vineae, H. uvarum, H. guilliermondii or Candida zemplinina 
displayed higher synthesis rates for isobutyric acid [3,19]. However, it has been stated that this group of yeasts does not present a distinct biosynthesis of fatty acids. In fact, the use of mixed fermentations including $S$. cerevisiae and non-saccharomyces can modify the chemical profile of the single $S$. cerevisiae model. In general terms, this combination shows a reduction in the amount of medium-chain fatty acids, as it happens when inoculating S. cerevisiae with H. osmophila. Even though, the utilization of a mixture of C. stellata and S. cerevisiae could increase the amount of hexanoic and octanoic acids, followed Pichia fermentas. Similarly, the application of sequential inoculations based on S. cerevisiae and non-saccharomyces usually provides wines with lower concentrations of fatty acids [3]. The use of mixed or sequential fermentations can have benefits to regulate the content of these medium chain fatty acids, since their excessive presence may provide negative aromas with greasy, rancid and cheesy notes [3,32].

\subsection{Higher Alcohols}

The most abundant alcohols in wine, apart from ethanol and glycerol, are diols, higher alcohols and esters. Ethanol provides viscosity, balance taste and fix odors while higher alcohols and glycerol strongly contribute to the aroma complexity of wine and to the overall mouthfeel of wine. Higher alcohols are the result of the catabolism of amino acids by a process known as Ehrlich reaction, which affect directly or indirectly to the synthesis of aroma compounds. Higher alcohols are also involved as ester precursors which are important compounds in wine aroma [5,19]. Major higher alcohols are 1-propanol, isobutanol and isoamyl alcohol. Other important volatiles are the precursors of aromatic alcohols such as 2-phenylethanol, tyrosol or tryptophol and other higher alcohols but present in lower amounts, like 2-methylbutanol-1, 3-or methyl-1-butanol-1. Moderate concentrations of some of the volatiles considered to have high odor intensity, such as 3-methyl-1-butanol, 2-phenylethanol or isoamyl alcohol, can provide positive impact in the wine providing flower, honey and fruit aroma notes. However, the higher alcohol concentration plays a key role in the complexity of the aroma composition. Optimal alcohol values under $300 \mathrm{mg} / \mathrm{L}$ provide fruity and flowery notes, whereas alcohol values above $400 \mathrm{mg} / \mathrm{L}$ become negative by adding pungent and unpleasant aromas [2,3,8,19]. Among the different fermentation parameters that affect the final concentration of alcohol in wine, yeast strain is one of the key parameters followed by temperature, $\mathrm{pH}$ or oxygen, apart from grape ripeness and variety [33]. Higher alcohol synthesis has been widely studied and related to different species and/or inoculation protocols to obtain wines with an equilibrated higher alcohol composition. Different works have evaluated the efficiency of $S$. cerevisiae in terms of higher alcohol production [34,35]. Generally, no significant differences have been observed for 1-propanol while isobutanol, isoamyl alcohol, 3-methyl-1-butanol or 2-phenylethanol production seems to be strain-dependent and related to the presence of $S$. cerevisiae, both as pure or mixed cultures. In general terms, H. uvarum, C. zemplinina or P. anomala are considered as high alcohol producers, used both as single and mixed (with $S$. cerevisiae) fermentation agents $[3,8,19]$. Nevertheless, the single application of non-saccharomyces yeasts has been stated to produce lower amounts of total alcohols than $S$. cerevisiae and so, a reduction of the final amount of higher alcohols when using mixed cultures [36]. Indeed, H. osmophila, H. guilliermondii and P. membranifaciens were demonstrated to produce lower amounts of higher alcohols when tested against $S$. cerevisiae, even though $H$. osmophila provided high levels of 2 phenylethanol and isoamyl alcohol. Similarly, for the genus Candida, C. zemplinina has been described to synthesize 2-phenylethyl, glycerol and low amounts of ethanol and acetic acid. This combination has prompted its classification as fructophilic species, whereas C. stellata is classified as low producer. Another study with H. uvarum strains displayed variability in all produced higher alcohols except for isobutanol whose production seems to be boosted by Hanseniaspora. Indeed, another species, $H$. guilliermondii, also has a higher production rate of isobutanol than $S$. cerevisiae. Besides, same species synthesized very low amounts of 1-propanol [3,8,19]. 


\subsection{Esters}

Esters are another relevant group, also responsible for the aroma complexity of wines with more than 160 representatives already identified. From a chemical point of view, they can be classified into ethyl fatty acid esters or acetate esters. In the first category, ethyl hexanoate, ethyl octanoate, and ethyl decanoate are the most abundant ones. In these molecules, ethanol represents an important contribution to their structure. In the second class, higher alcohols are essential for the formation of these esters. The major acetate esters are isobutyl acetate, amyl acetate, hexyl acetate, ethyl acetate (fruity aroma), isoamyl acetate (banana aroma) and 2-phenylethyl acetate (2PA), which has been described to provide honey, fruity and floral aromas to the wine $[2,3,7]$. In white wine, the main fatty acid ethyl esters include ethyl butanoate, caproate, caprylate, caprate and laurate. As other esters, they can also provide fruity tones that become softer with the increasing number of carbons in their chemical structure of the formation of these esters depends on the selection of yeast species and other fermentation parameters such as low temperatures, are [7]. Different yeasts have been used to give complexity to wines through ester production including S. cerevisiae but also non-saccharomyces species such as Candida, Hansenula and Pichia since their differential enzymatic mechanisms allow the introduction of novel aromas in wines [3]. In general terms, esters have positive effects on the aroma of young wines, especially in those with neutral flavors. Nevertheless, as it happens in the case of higher alcohols, excessive amounts of esters may induce negative effects on the quality of wine. A high concentration of esters can hidden varietal aromas and simplify the composition of aroma of the final product or spoil wine, for instance, if ethyl acetate exceeds 150-200 mg/L [2,19].

\subsection{Volatile Phenols}

The positive aroma notes of this group of molecules have been mainly related to the aging process where the main volatile phenols are guaiacol, 4-methyIguaiacol, 4ethylguaiacol, phenol, o-cresol or vanillin. The enzymes involved in these metabolic steps are mainly associated with $\mathrm{LAB}$, such as $\beta$-glucosidases, proteases, esterases, citrate lyases and phenolic acid decarboxylases. In fact, many malolactic fermentations take place in oak barrels even though LAB can synthesize oak-like derived compounds from non-volatile phenols present in wine. Among the non-volatile phenols present in grapes it is common to find phenolic acids (caffeic, ferulic and $p$-coumaric) or their tartaric esters (caftaric acid, feruloyl tartaric acid, $p$-coumaroyl tartaric). LAB have the capacity to metabolize cinnamic acids, such as $p$-coumaric or ferulic, that through a decarboxylation step can be transformed into 4-vinyl guajacol and 4-vinylphenol. Thus, the use of LAB to obtain these compounds before the aging step has gained attention since it can help to modify the aroma complexity of wine. LAB can transform non-volatile phenols that contribute with unpleasant aromas such as pharmacy, smoke, forest, leather or pepper, into volatile pleasant ones, such as those related to vanillin, methyl vanilla or homovainyl alcohol. Apart from those that can be synthesized during fermentation stages due to their presence in grapes, another volatile phenols not present in grapes can be found in wines, i.e., acetovanillone $[1,7,31]$.

\section{Saccharomyces Cerevisiae}

Saccharomyces cerevisiae is the most known yeast regarding the winemaking process. The historical importance of this yeast comes from far below as it was the first yeast observed by Antoine van Leeuwenhoek using a primitive microscope and it was then described as a living agent of transformation by Louis Pasteur [37]. As "agent of transformation", S. cerevisiae was domesticated from the production of food and beverages such as bread and wine or beer, respectively [38,39]. Apart from its traditional application in food and alcoholic beverages, S. cerevisiae has been also used for fuel production, for the expression of engineered designed proteins and as genetic model organism [40]. Particularly, in wine production, S. cerevisiae was selected and has been used for centuries due to its specific characteristics: high fermentative metabolism, suitable fermentation kinetics, low acetic acid production, resistant character against higher concentrations of sugar, ethanol and 
sulfur dioxide and also, the production of pleasant aromatic compounds [38,41]. Therefore, in 1890 , S. cerevisiae cultures started to be inoculated to wine and commercial starters were introduced into the market [39]. Since this moment, different approaches have been followed up such as guided or mixed fermentations for optimizing wine production and its organoleptic characteristics [19].

S. cerevisiae possesses a specific metabolism that regulates the production of volatile and aroma molecules. As it can be seen in Table 1, this yeast contributes to many of the aroma compounds classes present in wine (fatty acids, higher alcohols and esters), although varietal compounds and pre-fermentative compounds also contribute to the final wine complex aroma [2,3]. Some of these groups have been intensively studied using S. cerevisiae fermentations and also, different enzymes have demonstrated a key role in their formation, such as alcohol acetyltransferases (Atf1p and Atf2p), isoamyl alcohol acetyltransferase or ethanol acetyltransferase (implied in the formation of acetate esters) or the acyl-CoA:ethanol O-acyltransferase, related with the production of the ethyl esters [5]. In general terms, S. cerevisiae produce lower amounts of higher alcohols and poorer extracellular enzymes involved in the hydrolysis of structural components when compared to other non-saccharomyces species. However, it produced higher quantities of esters or acetaldehyde [42]. Ethanol content also influences sensory characteristics, providing fruity, flowery or acid aromas to wine, in specific concentrations [5]. On the other hand, sulfur compounds have been associated with negative or unpleasant aromas thus, poorer producers of sulfur dioxide $S$. cerevisiae strains are frequently selected. Besides, terpenoids, can be de novo produced by S. cerevisiae through the mevalonic acid pathway, constituting an alternative pathway [43].

Apart from those desirable characteristics of yeasts, there are other variables that can affect or have consequences on the aroma profile [43]. For instance, in the case of sparkling wines, a recent study showed that depending on the employed strain of S. cerevisiae and the period of aging, different aroma profiles were obtained. The study evaluated the production of ethyl esters (sour and apple aromas) and alcohols (herbaceous, rose, sweet aromas). It was demonstrated that flocculent yeasts produced higher amounts of these volatile compounds after 3 months whereas yeasts with higher autolytic ability produced more elevated amount of esters and alcohols after 6 months [44]. Other aspect that influences different aromatic profiles is geographical origin of indigenous yeasts. Some authors have pointed out that aroma or terroir includes a microbial aspect, since its sensory profile varies depending on the microorganisms implied. Particularly, the specific "signature" of some S. cerevisiae indigenous populations is linked to certain regions and environment conditions $[45,46]$. In this sense, it has been found that different genotypes (original from a specific region) are related to changes in the released compounds and thus, in the aroma profile. For instance, different genotypes from New Zealand were compared and it was found that depending on the area, some genotypes produced higher amounts of $\beta$-damascenone (apple, honey and floral aromas), higher concentrations of ethyl isobutyrate and ethyl-2-methyl butanoate (apple and sweet fruit aromas) or ethyl butanoate (peach, apple and sweet aromas) [47]. Another work reported that, independently from the substrate characteristics, the production of specific aromatic compounds is related with yeast origin, showing differences in the amounts of acetic acid, acetoin, acetaldehyde, n-butanol and 2,3-butanediols, 2-methyl-1-butanol and 3-methyl-1-butanol, among others [45]. Therefore, the current thinking is that origin, genotype and phenotype of $S$. cerevisiae strains affect quality parameters of wine and has prompted the interest on selecting autochthonous yeasts over commercial ones [46].

Nutrients (e.g., initial nitrogen and lipids) concentration and temperature are other parameters that can influence aroma. A recent study evaluated how specific environmental conditions affect the production of volatile compounds and found that their effects depended on the target compounds. However, authors found that the strain was determinant for the effects of environmental parameters [48]. Regarding higher alcohols, initial nitrogen content played a fundamental role exerting a negative quadratic effect for 2-phenylethanol 
and it positively affected propanol production. In general, temperature and lipid content were positively correlated with the synthesis of isobutanol and isoamyl alcohol. Interactive effects were also found between parameters. Therefore, it has been suggested that the disposal of nitrogen sources (e.g., amino acids) and the production of aroma compounds by $S$. cerevisiae do not follows linear relationships $[48,49]$.

\section{Non-Saccharomyces Species}

\subsection{Yeasts}

\subsubsection{Major Yeasts}

Hanseniaspora/Kloeckera

Hanseniaspora is a genus of apiculate yeasts whereas the name Kloeckera is applied to its anamorph form. Nowadays, the Hanseniaspora/Kloeckera group, which is naturally present in grapes, comprises ten species: H. valbyensis, $H$. guilliermondii, H. uvarum, $H$. opuntiae, $H$. thailandica, H. meyeri, H. clermontiae; H. vineae, H. osmophila and H. occidentalis [50]. This genus is widely found in grape must and is characterized by its low fermentative power but also for its production of wine volatile compounds and its contribution to wine complexity [51]. Although several groups of volatile molecules are produced in wines during their fermentation with Hanseniaspora spp., this genus has been characterized as high producer of volatile fatty acids, esters, aldehydes and sulfur compounds but low producer of higher alcohols [19]. The most characteristic compounds produced by Hanseniaspora spp. that confer positive aroma to wines are acetate esters (isoamyl acetate, ethyl hexanoate, ethyl caprylate, phenylethyl propionate, ethyl caprate, ethyl 9-decenoeate, ethyl acetate, phenethyl acetate, beta-phenylethyl acetate, benzyl acetate and 2PA) [50,52-54] and aldehydes, such as acetaldehyde, benzaldehyde, 4-ethylbenzaldehyde and benzene acetaldehyde [50]. In addition, some alcohols (glycerol, 1-pentanol, phenethyl alcohol, benzyl alcohol), carboxylic acids (hexanoic acid, octanoic acid) and terpenes (limonene) are implicated in the wine flavors [50,52].

At industrial scale, $H$ uvarum, $H$. vineae and $H$. guilliermondii are the most appropriate species to achieve an intense wine flavor and aroma complexity [55]. As previously stated, these microorganisms can naturally appear and develop spontaneous fermentation or they can be inoculated in mixed fermentations with $S$. cerevisiae. These strains contribute with positive oenological properties to wines conferring mainly floral and fruity notes such as chocolate, fig and tobacco (H. uvarum) [56], fruity-sweet coconut and woody or vanilla aromas (H. vineae) [57] and rose and honey sensory markers (H. guilliermondii) [53]. In mixed cultures, they can contribute with an enhancement of the production of volatile compounds. For instance, H. guilliermondii contributed with higher levels of 2PA to wine and $H$. uvarum could increase their isoamyl acetate content, when inoculated respectively alone. On the other side, an increase of the content of other compounds such as methionol, acetic acid-3-(methylthio) propyl ester or 4-(methylthio)-1-butanol, among others, occurred when they were inoculated with $S$. cerevisiae [58]. Further, 2PA is one of the compounds more studied in terms of aroma implications within species of Hanseniaspora. Different researchers have found that the mixed culture of both, $H$. vineae and $H$. uvarum with S. cerevisiae, provoke a synergistic effect on the production of 2PA, enhancing their floral, fruity (banana, pear, apple or citric fruits, among others) and honey aromas [23,59]. In addition, mixed cultures of $H$. guilliermondii with $S$. cerevisiae, have shown an increase of higher alcohols, acetate esters and acetaldehyde, while a reduction of ethanol, hydrogen sulphide and ethyl esters, when S. cerevisiae was used alone [60]. Another species of this genus, in this case, H. opuntiae was evaluated in mixed culture and the sensory analysis of the resulting wine, showed a higher floral and sweet aroma. This increment was related to the major production of some compounds such as phenylethanol or 3-methyl-1-bu-tanol and minor levels of decanoic and octanoic acid [61]. Apiculate yeasts have sometimes been related with the release of unpleasant flavour compounds but as previously stated, they can positively influence aroma profile in certain cases [51]. Therefore, authors are cautious when considering this genus as high intra-strain variability is found regarding their production of aroma compounds [21,51]. 
Likewise, other parameters can influence aroma. Regarding the time of inoculation, a recent study tried to elucidate the differences in the volatile aroma compounds when occurring a sequential or a simultaneous fermentation of H. uvarum and S. cerevisiae. Kai et al. (2018) observed that volatile phenols and acetate ester levels were higher in sequential fermentation, suggesting that this could be linked to a population ratio H. uvarum/S. cerevisiae higher than 1 [62]. Another study proved that the simultaneous inoculation of H. uvarum and S. cerevisiae caused an increase of medium-chain fatty acid ethyl ester content, improving floral, berry, tropical and temperate fruity aromas whereas sequential inoculation also improved floral and tropical fruity traits but produced an unpleasant "nail polish" odor [63]. Furthermore, must or wine composition also influences aroma profile. In this sense, low initial levels of YAN in the case of Ecolly wine were related to higher levels of ethyl esters and fatty acids whereas elevated content of YAN in the case of Cabernet Sauvignon must, motivated the expression of ATF1 gene and thus, an increment of the acetate ester production [62].

Table 2 describes the influence of different Hanseniaspora strains in the wine aroma profile. In general and from a chemistry point of view, the aroma improvements are explained by the production of higher concentrations of acetate esters like 2PA and isoamyl acetate, terpenes, medium-chain fatty acid-ethyl esters, benzenoids and decrease of higher alcohols [55].

Table 2. Different aroma compounds produced by yeast which confers good characteristics and pleasant aromatic properties to wine.

\begin{tabular}{|c|c|c|c|c|}
\hline Yeast & Compounds & Matrix & Aroma (Odour Descriptor) & Ref. \\
\hline $\begin{array}{l}\text { H. uvarum and } \\
\text { C. stellata }\end{array}$ & Benzyl alcohol & $\begin{array}{c}\text { Cabernet sauvignon } \\
\text { wine }\end{array}$ & Chocolate, fig and tobacco & [56] \\
\hline H. vineae & Beta-phenylethyl acetate & $\begin{array}{l}\text { Red wine from } \\
\text { Uruguay (Tannat } \\
\text { cultivar) }\end{array}$ & Intense fruity & {$[54,56]$} \\
\hline H. vineae & P-hydroxybenzyl & Wine & $\begin{array}{l}\text { Fruity, coconut, woody, } \\
\text { vanilla }\end{array}$ & [56] \\
\hline H. guilliermondii & Beta-phenylethyl acetate ester, 2PA & Wine & $\begin{array}{c}\text { Rose, honey, fruity and } \\
\text { flowery }\end{array}$ & [53] \\
\hline $\begin{array}{l}\text { H. uvarum and } \\
\text { H. guilliermondii }\end{array}$ & 2-phenylethanol & $\begin{array}{l}\text { Grape must from } \\
\text { Douro, Portugal }\end{array}$ & Fruity and flowery & [58] \\
\hline H. uvarum & Ethyl acetate & Wine & Fruity & [64] \\
\hline H. uvaum & $\begin{array}{l}\text { Terpenes, C13-norisoprenoids, } \\
\text { volatile phenols, terpineol and } \\
\text { linalool oxide }\end{array}$ & $\begin{array}{l}\text { Ecolly and Cabernet } \\
\text { Sauvignon wine }\end{array}$ & Tropical fruity and floral & [62] \\
\hline H. vinae & 2PA, isoamyl acetate and esters & Chardonnay wine & $\begin{array}{c}\text { Banana, pear, apple, citric } \\
\text { fruits, guava }\end{array}$ & [65] \\
\hline H. vinae & Phenyl ethyl acetate & Macabeo must & Fruity, floral and honey & [66] \\
\hline C. pulcherrima & Ethyl acetate, Iso-amyl acetate & Wine & Fruity, sweet and banana-like & [17] \\
\hline C. zemplinina & $\begin{array}{l}\text { Hexyl acetate, ethyl hexanoate, ethyl } \\
\text { heptanoate, ethyl dodecanoate and } \\
\text { ethyl butanoate }\end{array}$ & Barbera wines & $\begin{array}{l}\text { Apple, fruit, herb, sweet } \\
\text { or waxy }\end{array}$ & [67] \\
\hline M. pulcherrima & Phenol,2,6-dimethoxy & White wine & Smoky notes & [68] \\
\hline
\end{tabular}


Table 2. Cont.

\begin{tabular}{|c|c|c|c|c|}
\hline Yeast & Compounds & Matrix & Aroma (Odour Descriptor) & Ref. \\
\hline R. mucillaginosa & $\begin{array}{c}\text { Terpenic compounds } \\
\text { (b-damascenone, geraniol, } \\
\text { citronellol, linalool, b-terpineol) }\end{array}$ & $\begin{array}{c}\text { Irpinian wines } \\
\text { (Aglianico and Fiano } \\
\text { wines) }\end{array}$ & $\begin{array}{l}\text { Floral, sweet and ripened } \\
\text { fruit }\end{array}$ & [69] \\
\hline R. mucillaginosa & Terpenols & Chinese wine & Fruity and floral & [70] \\
\hline R. mucillaginosa & $\begin{array}{l}\text { C6 compounds (1-hexanol) and faty } \\
\text { acids }\end{array}$ & Chinese wine & Grass and unpleasant fatty & [70] \\
\hline R. mucillaginosa & $\begin{array}{l}\text { 3-hexene-1-ol, neroloxide, acetates } \\
\text { and ethyl groups }\end{array}$ & Ecolly dry white wine & $\begin{array}{l}\text { Citrus, sweet/acid fruit, } \\
\text { berry, floral }\end{array}$ & [71] \\
\hline P. anomala & Isoamyl acetate & Wine & Banana & [53] \\
\hline P. kluyveri & 2PA, ethyl octanoate & Sparkling wine & $\begin{array}{c}\text { Fruity, rose, sweet, honey } \\
\text { flavors and pineapple, pear, } \\
\text { soapy }\end{array}$ & {$[55,72]$} \\
\hline T. delbrueckii & $\begin{array}{l}\text { Ethyl butyrate, ethyl acetate, ethyl } \\
\text { hexanoate and ethyl hexanoate }\end{array}$ & Sparkling wine & $\begin{array}{c}\text { Fruity, sweet, pineapple, } \\
\text { green apple, brandy, } \\
\text { wine-like, strawberry }\end{array}$ & [22] \\
\hline T. delbrueckii & $\begin{array}{l}\text { Ethyl propanoate, ethyl } \\
\text { isobutanoate, ethyl } \\
\text { dihydrocinnamate and isobutyl } \\
\text { acetate }\end{array}$ & $\begin{array}{l}\text { Sauvignon blanc and } \\
\text { Merlot must }\end{array}$ & Fruitiness and complexity & [26] \\
\hline T. delbrueckii & $\begin{array}{l}\text { Isoamyl acetate, hexyl acetate, ethyl } \\
\text { hexanoate and ethyl octanoate }\end{array}$ & Juice from Syrah grapes & Fresh and fruity & [73] \\
\hline T. delbrueckii & 3-sulfanylhexan-1-ol & $\begin{array}{c}\text { Sauvignon Blanc grape } \\
\text { must }\end{array}$ & Grapefruit/passion fruit & [74] \\
\hline
\end{tabular}

Candida

The genus Candida is a collection of approximately 150 asporogenus yeast species from which $11 \%$ are agents of human infection since when they are ingested, they can enter to the bloodstream and cause fungaemia [75]. Besides, several studies show the significant impact of Candida spp. on the production of metabolites that affects the flavor and aroma of wines during fermentation on its own and together with $S$. cerevisiae $[17,76]$. Generally, it has been related to high production of esters, sulfur compounds and higher alcohols and low production of volatile fatty acids, aldehydes and volatile phenols [19].

Among this genus, the most known and studied Candida species could be C. albicans, C. stellata (reclassified as C. zemplinina) or C. pulcherrima (telemorphic form of Metschnikowia pulcherrima), among others [21,51]. All these species have been studied in different times. C. albicans was able to produce higher levels of farnesol and farnesene (gardenia/perfume aroma) [21]. C. stellata was found to intensify the apricot, honey and sauerkraut aromas when used alone in monoculture and increase the production of ethyl-acetate in sequential fermentation with $S$. cerevisiae on Chardonnay wine [77]. In addition, in a recent experiment, C. zemplinina was used in mixed cultures with $S$. cerevisiae and produce more aliphatic alcohols, certain aldehydes and ketones and esters (hexyl acetate, ethyl hexanoate, ethyl heptanoate, ethyl dodecanoate and ethyl butanoate) providing apple, fruit, herb, sweet or waxy aromas to wine [67].

C. pulcherrima/M. pulcherrima are commercial starters able to induce changes in wine's profile, especially in terpenes, volatile thiols and esters [51]. For example, it was observed that C. pulcherrima in mixed cultures produced higher levels of ethyl acetate and less undesirable volatile compounds [17], being ethyl acetate strongly linked to a fruity flavor in wines at levels of $0.2 \mathrm{~g} / \mathrm{L}$ [78]. The quantity of isoamyl acetate formed by C. pulcherrima was significantly higher than that produced by non-saccharomyces yeasts in pure cultures 
exhibiting a sweet, fruity and banana-like aroma at levels upper $0.001 \mathrm{~g} / \mathrm{L}$ [17]. In another study, M. pulcherrima non-flocculant strain AWRI305 was tested in mixed culture with S. cerevisiae. The study showed an increment in the concentration of esters (especially, ethyl acetate and 2-methylbutyl acetate) and sulfur compounds. In this case, compared with $S$. cerevisiae alone, these wines showed lower content in brown tint and higher in red fruit aroma [79]. Likewise, another study showed that M. pulcherrima (sequential culture with S. cerevisiae) produced higher content in higher alcohols (specially 3-methyl1-butanol and 2-methylpropanol), lower amounts of acetaldehyde, a severe decrease of butyl acetate and quite higher production of volatile phenols. These changes motivated the perception of smoky and flowery notes by tasters [68]. In addition, M. pulcherrima has been related to the production of low-alcohol wines, a desirable characteristic for the wine industry [80]. In this context, other authors have proposed this species and C. zeylanoides for this purpose, as they were poorer sugar consumers and effectively reduced ethanol content. M. pulcherrima has shown high production of higher alcohols (isobutanol and 2-phenylathanol), ethyl propionate, ethyl acetate and diacetyle, when compared to other species thus, being potentially suitable as inoculum [81]. Other strains like C. molischiana could produce terpenols and alcohols from a glycoside matrix. It has been also described the production of aldehydes by Candida krusei and volatile phenols and sulfur compounds by other species of Candida genus [82].

\subsubsection{Minor Yeasts}

Spontaneous grape-must fermentation can also begin with the growth of other minor species belonging to genera such as Rhodotorula or Pichia, among others. These yeasts with low fermentative capacity can confer wine flavor and aroma complexity by increasing the amounts of the volatile compounds responsible for the fruity aroma, through hydrolysis of aroma precursors caused by enzymatic activity [83]. Studies reported that glycosidases from minor yeast have also remarkable potential to improve aroma complexity and regional characteristics of wine [70]. Table 2 shows various examples of non-saccharomyces yeasts and their implication in wine aroma.

\section{Rhodotorula}

Rhodotorula spp. has been referred by some authors as high producer of esters and isoamyl acetate [19]. One of the most studied species is Rhodotorula mucillaginosa [21]. R. mucillaginosa possesses high extra-cellular glycosidase activity able to convert the glycosylated form of terpenes into aromatic compounds. For example, a general increase of terpene compounds ( $\beta$-damascenone, geraniol, citronellol, linalool, $\beta$-terpineol) was observed in Aglianico and Fiano wines from Italy (Irpinian wines) [69]. The application potential of a Chinese strain of $R$. mucillaginosa to wine aroma enhancement was also reported [70]. In other case, an increase in the concentration of volatile compounds (neroloxide, alphaterpineol, farnesol, limonene, linalool, citronellol, geraniol, geranyl acetone and nerolidol) was observed in samples treated with glycosidase extracts from $R$. mucilaginosa. Moreover, the enzyme treatments improved the content of volatile phenols, $\mathrm{C}^{6}$ compounds (1-hexanol) and fatty acids. Terpenic compounds and benzene compounds are positive aromatic compounds, while $\mathrm{C}^{6}$ compound, volatile phenols and fatty acids could release unpleasant aromas, depending on their concentration on the final wines [70]. A recent study also assessed the glycosidase activity and the main compounds related with the fermentative aroma produced by $R$. mucillaginosa which were 1-butanol, isoamyl alcohol, ethyl acetate, ethyl lactate and phenyl ethyl alcohol [71].

Pichia

The genus Pichia has been described as producer of esters, especially ethyl acetate and isoamyl acetate [19]. The yeast Pichia kluyveri is usually co-inoculated together with S. cerevisiae since it is unable to ferment to dryness on their own [84]. The use of P. kluyveri to increase the levels of terpenic compounds in sequential fermentations with S. cerevisiae had 
been previously reported [55]. This study also described that this yeast was able to produce high levels of esters, specially 2PA and ethyl octanoate [55]. The characteristic fruity, rose, sweet, honey flavors of wine and other grape-derived alcoholic beverages are primarily due to 2PA and ethyl octanoate, thus they provide pineapple, pear, soapy odors [72]. It has been also reported that $P$. anomala wine yeasts produce increased concentrations of esters with a fruity aroma. The yeast was found to be a potent isoamyl acetate producer and the characteristic banana-like aroma of wine was primarily due to this compound [53]. Other study showed that $P$. kudriavzevii in mixed cultures exhibit a chemical profile with higher levels of glycerol, ethyl acetate and isoamyl acetate and less content in fatty acids, higher alcohols and phenyl ethanol. These profile resulted in a floral, sweet and fruity aromas [61] Similarly, a recent study showed that wines produced in simultaneous fermentation with P. kudriavzevii and S. cerevisiae had lower volatile acidity, higher amounts of esters and lower higher alcohols, fatty acids, benzene derivatives and $\mathrm{C}^{6}$ compounds concentration. In addition, the aroma profile and whole flavor and quality were improved and wines obtained higher scores in fruity and floral aromas, appearance and mouthfeel [24].

\section{Torulaspora}

As aforementioned, other genera and species have been also widely studied for their implication in the aroma profile of wine. This is the case of Torulaspora delbrueckii which has shown positive impact on wine's aroma and increasingly importance [85]. T. delbrueckii (anamorph Candida colliculosa, synonym Saccharomyces rosei) [19] has shown strain variability regarding aroma profile and some of them exhibited low production of acetaldehyde and acetoin, both positive attributes. However, it produced small amounts of higher alcohols (being isoamyl alcohol and $\beta$-phenylethanol, the major compounds), acetate esters and ethyl esters of fatty acids. This way, it has been suggested that they slightly contribute to aroma complexity when compared to other non-saccharomyces organisms [85]. Nevertheless, a recent study investigated the effects of T. delbrueckii alone or in mixed culture with S. cerevisiae and their volatile compounds profile. In general, the presence of T. delbrueckii was associated with an increase of the fruity, sweet, pineapple, green apple, brandy, wine-like and strawberry sensory descriptors [22]. Other studies have related it to high production of isovaleric acid, ethyl propionate, 1-butanol and low production of acetic acid [81]. Also other authors confirm the low acetic acid production, while an increase in higher alcohols concentration (1-butanol) was observed [68]. Another study demonstrated that $T$. delbrueckii was related with higher concentrations of esters and differences were observed between mixed and sequential fermentation, promoting polyols synthesis (2,3-butanediol and 1,2-propanediol) and 1-butanol, 3-ethoxy-1-propanol and furaneol production, respectively [73]. At last, combinations of more than one species of non-saccharomyces yeasts have been also researched [19].

\subsection{Bacteria}

\subsubsection{Lactic Acid Bacteria}

Given the specific fermentation conditions, high ethanol production, presence of sulfur dioxide and low $\mathrm{pH}$ and nutrients concentrations, the environment turns out to be inhospitable for most bacteria genera. Nevertheless, lactic acid bacteria (LAB) and acetic acid bacteria $(\mathrm{AAB})$ have managed to survive. $\mathrm{LAB}$ are in charge of the malolactic fermentation (MLF), also known as secondary fermentation which takes place in most of red wines and some white wines, performing the enzymatic decarboxylation of L-malic acid to L-lactic acid and carbon dioxide. This deacidification of wine reduces the sour taste that an excess of malic acid could give $[5,86]$. Simultaneously, as a result of LAB activity, volatile compounds are released enhancing aroma complexity with fruity or buttery notes, and reducing others such as vegetal or grass aroma. MLF also contributes to the microbiological stability of wine, decreasing the possibilities of spoilage by unwanted microbiota $[5,87]$. Within the LAB group, researchers have identified four main genera, the bacilli Lactobacillus and three cocci, Oenococcus, Pediococcus and Leuconostoc $[87,88]$. 
Among these genera, Oenococcus oeni is species most usually linked to MLF due to its resistance to fermentation conditions in red and white wines. [89]. It shows a welladapted response to highly acidic wine conditions and better enzymatic activity than other selected starters [90]. Within this genus barely three have been isolated in must, $O$. oenis, $O$. alcoholitolerans [91] and O. kitaharae [92]. Several examples of the implications of Oenococcus and other LAB species is compiled in Table 3.

Table 3. Different aroma compounds produced by lactic and acetic acid bacteria strains.

\begin{tabular}{|c|c|c|c|c|}
\hline Bacteria & Compounds & Matrix & Aroma & Ref. \\
\hline \multicolumn{5}{|c|}{ Lactic Acid Bacteria } \\
\hline \multirow[t]{2}{*}{ Lactobacillus brevis } & Methanethiol & \multirow{2}{*}{ Merlot wine } & Unpleasant sulfur aroma & \multirow{2}{*}{ [93] } \\
\hline & 3-(methylsulfanyl) propan-1-ol & & Meaty aroma $(<10 \mu \mathrm{M})$ & \\
\hline Lactobacillus plantarum & $\begin{array}{l}\text { Linalool, } 2 \text { phenyl-ethanol, } \\
\text { 2,3-butanediol, 4-terpineol and geraniol }\end{array}$ & Fiano wine & $\begin{array}{l}\text { Floral, fruity and spicy } \\
\text { aroma }\end{array}$ & [94] \\
\hline \multirow[b]{2}{*}{ Lactobacillus plantarum } & Terpenes, limonene and linalool & \multirow[b]{2}{*}{ Synthetic wine } & Flowery-citric aroma & \multirow[b]{2}{*}{ [95] } \\
\hline & $\begin{array}{l}\text { Benzyl alcohol and } \\
\text { b-phenyl-ethyl-alcohol }\end{array}$ & & Rose-like odor & \\
\hline $\begin{array}{l}\text { Oenococcus oeni and } \\
\text { Lactobacillus spp. }\end{array}$ & $\begin{array}{l}\text { Terpenes, norisoprenoids, phenols and } \\
\text { vanillins }\end{array}$ & Synthetic wine & $\begin{array}{l}\text { Alcohol and dried sensory } \\
\text { descriptors. Fruity aroma }\end{array}$ & [96] \\
\hline $\begin{array}{l}\text { Oenococcus oeni and } \\
\text { Lactobacillus plantarum }\end{array}$ & $\begin{array}{l}2 \text { phenyl-ethanol, 2,3-butanediol, } \\
\text { ethyl-lactate, terpenes and vanillate } \\
\text { derivatives }\end{array}$ & Shiraz wine & $\begin{array}{l}\text { Fruity, floral, earthy/nutty } \\
\text { aromas }\end{array}$ & [97] \\
\hline Oenococcus oeni & Ethyl esters & Wine & Fruit-like & [98] \\
\hline Oenococcus oeni & $\begin{array}{c}\text { 2-phenylethanol, terpenes, lactic acid } \\
\text { ethyl-ester and succinic acid, } \\
\text { diethyl-ester }\end{array}$ & Riesling wine & $\begin{array}{l}\text { Rose notes, fruity and } \\
\text { floral notes }\end{array}$ & [99] \\
\hline Oenococcus oeni & Hexanol, 3-methylbutylester, acid esters & Chardonnay wine & $\begin{array}{l}\text { Green and herbaceous, } \\
\text { banana notes and fruity } \\
\text { aroma }\end{array}$ & \\
\hline Oenococcus oeni & $\begin{array}{l}\text { Substituted ethyl esters: i.e., } \\
\text { (2S)-2-hydroxy-n-me-thylpentanoic acid }\end{array}$ & Merlot wine & $\begin{array}{l}\text { Black-berry and } \\
\text { jammy-fruit notes }\end{array}$ & [100] \\
\hline Oenococcus oeni & $\begin{array}{l}\text { Fruity esters and lower production of } \\
\text { alcohols and terpenes }\end{array}$ & $\begin{array}{l}\text { Black raspberry } \\
\text { wine }\end{array}$ & $\begin{array}{l}\text { Strong fruity and slight } \\
\text { notes of solvent and } \\
\text { herbaceous }\end{array}$ & [101] \\
\hline Leuconostoc & Phenyl-ethyl acetate & \multirow{2}{*}{$\begin{array}{l}\text { Black glutinous rice } \\
\text { wine }\end{array}$} & Sweet, floral aroma & \multirow{2}{*}{ [102] } \\
\hline Leuconostoc & 2,3-butanediol & & Buttery aroma & \\
\hline LAB commercial starter & $\begin{array}{l}\text { Diacetyl, ethyl acetate, ethyl lactate, } \\
\text { mono-ethyl and diethyl succinate }\end{array}$ & $\begin{array}{l}\text { Single-varietal red } \\
\text { wines }\end{array}$ & Fruity, smoked/toasted. & [103] \\
\hline \multicolumn{5}{|c|}{ Acetic Acid Bacteria } \\
\hline \multirow{2}{*}{ Acetobacter } & Ethyl esters & \multirow{2}{*}{$\begin{array}{l}\text { Highland barley } \\
\text { wine }\end{array}$} & Fruity, grape-like aroma & \multirow{2}{*}{ [104] } \\
\hline & Acetic acid & & Vinegar & \\
\hline Acetobacter aceti & 2PA, 3-methyl butanol, ethyl acetate & Pineapple wine & Floral-fruity aroma & [105] \\
\hline Gluconobacter & Tartaric and citric acid, ethyl esters & $\begin{array}{l}\text { Black glutinous rice } \\
\text { wine }\end{array}$ & Acid and fruity aroma & [106] \\
\hline
\end{tabular}

Lactobacillus genus is represented by approximately 30 species. Among them, L. plantarum, L. brevis, L. buchneri, L. hilgardii and L. fructivorans are the most found in must and wine. Also, other species such as L. bobalius, L. casei, L. collinoides, L. fermentum, L. kunkeei, L. lindneri, L. mali, L. nagelii, L. oeni, L. paracasei, L. paraplantarum, L. uvarum and L. vini have been also found $[88,107]$. Among them, L. plantarum is the most-liked by winemakers, due to its particular qualities: less nutrition requirements, lower inoculum concentration, 
tolerance to ethanol, high $\mathrm{pH}$ and sulfur dioxide and also, their diverse collection of enzymes able to enhance aroma profile in wines, such as glycosidases or esterases, among others [107-109]. For instance, the esterase activity of some LAB strains has been related to the increase of red- and black-berry fruit-like aroma and jam-fruit aroma as well [100].

In addition, research has been focused on the leverage of co-culture between $O$. oeni and L. plantarum, reporting more aroma complexity in mixed cultures [97]. For instance, a work evaluated the use of O. oeni and Lactobacillus strains and found that terpenes, norisoprenoids, phenols and vanillins were released in association, in general, with alcohol and dried sensory descriptors whereas oxidize notes were linked to phenyl-acetaldehyde and phenyl-acetic acid concentrations [96]. Furthermore, other studies have researched the application of LAB (i.e., O. oeni) together with mixed cultures (i.e., S. cerevisiae with T. delbrueckii). Results showed that volatile composition was quite different and scored better for global aroma than spontaneous MLF, which enhanced both pleasant and offflavors [101]. Another study stated that T. delbrueckii together with S. cerevisiae (sequential fermentation) created more MLF favorable conditions, since lower levels of sulfur dioxide and medium chain fatty acids, promoting the development of O. oeni [110].

Regarding the aroma compounds related to $\mathrm{LAB}$, diacetyl is the most important one. This compound is produced as a result of citric acid metabolism and can be further metabolized to 2,3-butanediol $[5,88]$. Therefore, citrate lyase enzyme plays an important role regulating the production of diacetyl. At low concentrations, it is related to yeasty, nutty and toasty aromas, whereas at high levels it produces sweet, buttery, creamy or milky aroma, sometimes linked to off-flavors. In this regard, some strains of L. plantarum do not present citrate lyase complex genes, and thus it is feasible to obtain wines with low diacetyl concentrations $[5,109]$. In addition, the perception of diacetyl is influenced by several factors such as the chemical composition of wines, the strain of LAB and the presence of sulfur dioxide, which can interact with diacetyl, decreasing wine's volatility [103,109].

Apart from Oenococcus and Lactobacillus, different pediococci species including P. damnosus, P. inopinatus, P. parvulus and P. pentosaceus have been isolated from wines. Among them, P. parvulus and P. damnosus are more commonly found in must and wine, due to its undesirable effects in wine, being associated with unpleasant aromas, bitterness and ropiness [88]. For instance, a study performed in pinot noir wine with P. inopinatus, P. parvulus and P. pentosaceus reported floral and fruit-like aromas [111]. It has also been reported the existence of other species, such as the recombinant strain, P. acidiltactici BD16, which could improve the aroma of wine due to the production of phenolics derived from MLF [112].

Leuconostoc strains are known by dominating the initial fermentation stages, conducting the MLF alongside with Lactobacillus and Oenococcus. Nonetheless, as acids levels raise, Leuconostoc is overcome by more acid tolerant Lactobacillus [113]. Further, its enzymatic activity involved in flavor and aroma has been barely studied; it has been reported protease and also citrate lyase activity $[114,115]$. In addition, L. paramesenteroides was renamed as Weissella paramesenteroides [88]. L. mesenteroides is the current dominant Leuconostoc strain in grape juice and must. More recent studies have positively correlated the presence of Leuconostoc sp. with floral and buttery-like aromas [102].

\subsubsection{Acetic Acid Bacteria}

Acetic acid bacteria (AAB) belong to the family Acetobacteraceae. They are classified as aerobic strict gram-negative bacteria, well adapted to sugar and high ethanol environments and able to oxidize ethanol to acetic acid. AAB have been spotted on grapes and red wine; being notably higher in damage and rotten grapes and they are mainly classified in Acetobacter or Gluconobacter [116]. In contrast to LAB, AAB presence is less desirable in winemaking; they are considered as spoilage organisms due to the formation of acetaldehyde and acetic acid, among other spoilage compounds [117]. In general, low acetic acid concentration provides vinegar-like sourness, nutty and sherry-like aroma to wine, associated with a reduction in fruity characters, but as the concentration raises, the effect 
is replaced by an unpleasant smell [117]. The sensory threshold for acetic acid becoming undesirable depends on the wine type, e.g., in Canadian sweet wines is $1.0-1.5 \mathrm{~g} / \mathrm{L}$ with an allowed maximum of $2.1 \mathrm{~g} / \mathrm{L}$ [118], while in dry wine, the concentration must not exceed $1.0 \mathrm{~g} / \mathrm{L}$ [119]. Another compound related to AAB metabolism that could affect wine quality is ethyl acetate, which can positively contribute to wine with floral or fruity-like aroma, though when it exceeds a specific threshold, it is also considered an undesirable compound. However, researchers have not reach an agreement about the establishment of that threshold [8].

Acetobacter are gram negative rods with an over-oxidative capacity, being able to oxidize ethanol to acetic acid to $\mathrm{CO}_{2}$ and water [119]. Generally, A. aceti and A. pasteurianus are the most often species isolated in wine [120,121]. Further, other related species are A. cerevisiae, A. malorum, A. tropicalis [121] or A. rancens and A. suboxydans found in Indian palm wine [122]. Acetobacter appearance is related to a bitter aroma and acid flavor, due to the excessive acetic acid concentration. Other aroma compounds as hexa- and octadecanoic acid ethyl esters, acetaldehyde, propionic and succinic acid have been correlated with Acetobacter metabolism [104].

Gluconobacter are also gram-negative rods, strictly aerobes, but unlike Acetobacter they are not able to oxidize acetate and lactate to carbon dioxide. Gluconobacter strains are frequently detected in grapes and can persist during the fermentation despite being relatively weak acetic acid resistant and less ethanol tolerant, since, they can be even inhibited by high levels of alcohol $[106,123,124]$. The presence of Gluconobacter has been positively correlated with the appearance of butanoic, lactic, citric and tartaric acids and other compounds such as benzyl alcohol, octanoic acid ethyl ester or ethyl 9-decenoate, among others [106]. However, it is worth mentioned that all these species together with Acetobacter species are majorly considered as spoilage microorganisms in wine, not used as starters and so, few investigation has been developed on their aroma implications beyond their acetic acid production.

\section{Strain Dependent Variability and Genetics Influence on Aroma Profile}

Variability on aroma profile has been related to different factors such as soil, grapes, climate, type of fermentation, medium and involved microorganisms, among others [1]. Focusing on the microorganisms and their implication in secondary aroma, genetics helps to understand the origin of these changes based on strains genotypes and phenotypes. In this regard, it is essential to mentioned S. cerevisiae, as it is considered as the best understood genetic model organism and the first eukaryote genome completely sequenced, the best annotated and also likely to be genetically manipulated and analyzed [40]. S. cerevisiae has shown genetic divergence, as the phenotypes that are currently used have demonstrated different characteristics related to wine production, such as resistance to sulfites [125]. This fact is also explained in aroma terms, as it has been shown that wild strains of $S$. cerevisiae and other Saccharomyces species produced earthy and sulfurous characteristics, whereas wine domesticated strains produced fruity and floral notes [125]. In this sense, the development of "omics" technologies and the improvement of high throughput sequencing has deeply contributed to further study the microbial community of wines and thus, its implication in wine aroma [126]. These advances have been mostly directed towards different objectives: (1) mapping yeasts and bacteria genomes to identify new genetic variants that are responsible for desirable aroma characteristics, (2) using analytical techniques to isolate, identify and quantify volatile compounds involved in aroma profile and (3) modifying yeast and bacteria strains to obtain a specific character or ability. Further, progress is aimed at transcriptomics, proteomics, exometabolomics, etc. studies [126,127].

As previously stated, yeasts have been historically selected according to different characteristics: ethanol tolerance, low residual sugars levels, low volatile acids production, low nitrogen consumption or high growth rate. Frequently, these features come determined by multiple quantitative trait loci (QTL), i.e., regions linked to certain phenotypic traits $[128,129]$. For instance, a recent study, found in S. cerevisiae 51 potential QTLs related 
to the production of monoterpenes and found that three of them (UDV060, VLG19-I-1 and VLG3-A-1) on three different chromosomes were placed closely to genes connected to the production of aroma compounds [130]. In addition, other studies have investigated different genetic mechanisms that affect wine aroma: changes in transcription levels of ALD6 gene (involved in the conversion of acetaldehyde into acetic acid), haploinsufficiency effects on YFL040W related to acetic acid and glycerol and succinic acid production or the epistatic gene-gene interactions resulting in heterosis of FLX1 and MDH2, two genes associated to succinic acid production [128]. Other studies have tried to integrate different omics, thus identifying new genes related to wine aroma and flavor in different strains of S. cerevisiae and confirming the production of fatty acids and ethyl and acetate esters by using high performance liquid chromatography (HPLC), gas chromatography-mass spectrometry (GC-MS) and microarray techniques [131]. Besides, research has been performed on the influence of nitrogen availability and related gene expression of S. cerevisiae. It was found that depending on nitrogen levels, a total of 46 genes were up-or down-regulated, proposing some of them to be used as molecular markers. In this sense, potentially different strains could be used to obtain different aromas [27,132]. In the same context, other authors have investigated the effects on volatile compounds production and gene expression of $S$. cerevisiae when adding branched-chain amino acids to must. Different genes were identified and associated to yeast growth and amino acids transport; also 25 metabolites (higher alcohols, esters, fatty acids and branched-chain amino acid) were detected, among which 2,3-butanediol and ethyl lactate levels were highly increased. Therefore, it was suggested that the addition of branched chain amino acids was able to enhance aroma complexity [133]. All these techniques and studies have been developed to characterise different strains of $S$. cerevisiae that are tightly connected to differences in aroma compounds production, such in the case of a Gewürztraminer wine where a specific strain was able to produce increased amounts of 2-phenylethanol and cis-rose oxide and the most complex aroma profile [134].

On the other hand, transcriptional analyses have been also carried out on nonsaccharomyces species mixed cultures with $S$. cerevisiae. It has been shown that culture in consortium of $S$. cerevisiae with other species can modify the genome transcriptional response of $S$. cerevisiae and differently express specific genes that encode for enzymes linked to the production of aroma compounds [60]. For instance, several studies have investigated T. delbrueckii. It has been demonstrated that the mixed cultures of these two species stimulates the transcription of some genes, such as those implied in the glucofermentative pathway, thus producing higher amounts of $\mathrm{CO}_{2}$ [135]. More recently, a transcriptome analysis of the same species revealed that the T. delbrueckii lower production of higher alcohols and acetate esters was explained by the absence of transcripts of key enzymes in those pathways whereas low levels of ethyl esters were related to down-regulation of fatty acids biosynthesis genes [136]. At last, a study bared that the presence of T. delbrueckii affect the transcriptional and phenotypic response of $S$. cerevisiae to ammonium nutrition by reducing its global effects. This way, mixed cultures produced higher concentrations of esters (i.e., acetic acid ethyl ester and lactic acid ethyl ester), providing fruity aroma to wine [137].

At last, it is also worth mention that according to the previously mention objective 3 , other approaches have been explored for modifying yeasts to achieve a specific characteristic. In this sense, genetic modified organisms (GMOs) have been developed to fulfil those requirements but also other methodologies have been used to generate enhanced wine organisms not considered as GMO, such as clonal selection, random mutagenesis or sexual hybridization [129]. Further, research has been focused on grapes and its genetic base regarding the synthesis of aroma compounds during fermentation [138]. Therefore, the development of new "omics" technologies and related sciences is necessary for the elucidation of the transcriptional and genetic mechanisms involved in wine aroma formation. 


\section{Future Perspectives and New Approaches}

The fermentation of grape must and the production of premium quality wines is a complex biochemical process that involves the interactions of enzymes from many different microbial species, but mainly yeasts and LAB [139]. In recent years, the oenological industry has undergone an important transformation, becoming a sector with constant changes and innovations. As it is described before, non-saccharomyces yeasts can positively influence aroma $[17,55,76]$. This quality improvement allows the production of innovative and differentiated wines. These yeasts can be introduced into the winemaking process to obtain differentiated wines that reflect the characteristics of a specific region. In this context, the study of the use of non-saccharomyces autochthonous cultures to produce wines with particular oenological and sensory characteristics, would allow to choose suitable candidates to be included in commercial mixed cultures [82]. The presence of the nonsaccharomyces species during the alcoholic fermentation might be of technological interest, but further studies on these yeasts for their biotechnological applications in winemaking are needed since the commercial assortment of non-saccharomyces cultures is still reduced [82]. It is yet possible to acquire some interesting species like Torulaspora delbrueckii, Lachancea thermotolerans, Metschnikowia pulcherrima, Schizosaccharomyces pombe and Pichia kluyveri. Other strains like Starmerella bacillaris, Meyerozyma guilliermondii and Hanseniospora spp., will probably be on market in coming years [55]. The use of non-saccharomyces yeasts can be also remarkable in regions where grape harvesting is put forward due to excessive rainfall and where the grape may contain insufficient amounts of aromatic compounds [70]. Bibliography shows big differences, depending on the non-saccharomyces strain employed due to the genomic diversity of those species and the importance of performing selective processes, such as those that were conducted for S. cerevisiae strains in the past [55]. In this sense, one parameter to consider is to identify yeast strains with a high level of $\beta$-glucosidase activity and to evaluate the hydrolysis characteristics of its enzyme extract.

Futures perspectives in the use of non-saccharomyces yeasts also aim to produce wines with lower alcohol content than those from pure Saccharomyces spp. starters [140]. Nowadays, consumers demand wine with low level of alcohol. Following this trend, winemakers search alternative methodologies to reduce the final content of ethanol in wine, especially in vineyards from warm climates where the grape over-ripening can occur giving an increase of sugar levels [140]. Inoculation of different non-saccharomyces yeast strains have been proposed for lowering alcohol levels in wine $(<2 \%$, depending on the yeast species and fermentation conditions) $[55,141]$. Different yeast species like Hanseniaspora/Kloeckera spp., Pichia spp. or Candida spp., which are predominant in the first stages of fermentation (up to $6 \%$ of alcohol content), consume sugars by respiration rather than fermentation. In this sense, non-saccharomyces species allow to reduce the initial ethanol content and would produce desirable levels of secondary metabolites, which will affect aroma profile [141]. Enzyme or osmotic filtration is another alternative strategy which can be used to reduce the content of ethanol in wine [140].

Nowadays, the production of efficient malolactic starter cultures has become another main challenge for oenological research [142]. There are several parameters to address when selecting $\mathrm{LAB}$ for possible use in a starter culture, such us their tolerance to acid conditions, high ethanol and $\mathrm{SO}_{2}$ concentrations, their compatibility with the selected yeast strains, adequate growth characteristics under winemaking conditions, the inability to produce biogenic amines and the lack of off-flavor or off-odor production [142]. Recent research highlights the importance of choosing specific LAB strains to obtain the desired wine, as specific flavors such as ethyl ester, volatile sulfides and glycosidic aroma compounds have been associated with specific strains. Since GMOs are not widely accepted by consumers, research is focused on identifying strains that can be used to modulate the aroma and flavor compounds of wine [88]. Finally, it is important to highlight that wine aroma is complex and contain an enormous chemical diversity. In this context, research should be also focused in developing simpler and non-targeted LC-MS methodology to study the entire volatile fraction of wine metabolome as well as other approaches such 2D GC, 
which has previously helped to solve the aroma on many complex matrices, including wine $[8,143]$.

\section{Conclusions}

Wine secondary aroma is complex and comes determined from the diversity of different chemical compounds. In the process of aroma formation, different factors play an important role. Different types of fermentation (single or mixed culture) and different strategies of inoculation (simultaneous or sequential) have shown differences on the final aroma profile. Further, other factors such as YAN, temperature, oxygen or time affect the sensory characteristics of wine. Regarding the whole chemical diversity found in wine and in particular, in volatile aroma compounds, those related with secondary or fermentative aroma are mainly higher alcohols and esters, together with volatile fatty acid and volatile phenols, and thus, they are the compounds mostly studied in research articles regarding wine aroma. In the last years, winemaking industry has undergone important transformations and despite S. cerevisiae is still used in production purposes for its desirable characteristics, non-saccharomyces yeasts have been highlighted as organisms that can positively influence aroma profile. According to provided data, there is a huge diversity of non-saccharomyces yeasts that can enhance or decrease the production of some aroma compounds, resulting in specific aroma attributes that are evaluated from a sensory point of view. Besides, MLF can affect wine aroma since LAB are tightly connected to the production of higher alcohols, esters and terpenes, together with norisoprenoids, phenols and vanillate derivatives in minor quantities. The main challenge still is to characterize their enzymatic activities and related genes. $\mathrm{AAB}$ are also revised since as spoilage microorganisms, they can negatively alter the aroma profile, although it has also been suggested that they can contribute with positive traits such as floral or fruity. Therefore, taking into account the diversity of yeasts and bacteria species and the necessities of the winemaking sector, genetics, transcriptomics and other sciences, aimed at decoding the strain dependent variability of species and its implications on wine aroma, are fundamental for the focused use of microorganisms and the achievement of wines with higher aroma complexity and pleasant characteristics that can fulfil the requirements of the consumers.

Author Contributions: Conceptualization, M.C., M.A.P. and J.S.-G.; methodology, M.C., M.F.-C., P.O., R.A.N., P.G.-O. and M.A.P.; formal analysis, M.C., M.F.-C., P.O., R.A.N., P.G.-O. and M.A.P.; investigation, M.C., M.F.-C., P.O., R.A.N. and P.G.-O.; writing-original draft preparation, M.C., M.F.-C., P.O., R.A.N., P.G.-O. and M.A.P.; writing-review and editing, M.C., M.A.P. and J.S.-G.; supervision, M.C., M.A.P. and J.S.-G.; project administration, M.C., M.A.P. and J.S.-G. All authors have read and agreed to the published version of the manuscript.

Funding: The research leading to these results was supported by FEDER under the program Interreg V-A Spain-Portugal (POPTEC) 2014-2020 ref. 0377_IBERPHENOL_6_E and ref. 0181_NANOEATERS_01_E; by Xunta de Galicia supporting with the Axudas Conecta Peme the IN852A 2018/58 NeuroFood Project and the program EXCELENCIA-ED431F 2020/12; by EcoChestnut Project (Erasmus+ KA202) that supports the work of M. Carpena; by Ibero-American Program on Science and Technology (CYTED-AQUA-CIBUS, P317RT0003) and by the Bio Based Industries Joint Undertaking (JU) under grant agreement No 888003 UP4HEALTH Project (H2020-BBI-JTI-2019), the JU receives support from the European Union's Horizon 2020 research and innovation program and the Bio Based Industries Consortium.

Institutional Review Board Statement: Not applicable.

Informed Consent Statement: Not applicable.

Data Availability Statement: No new data were created or analyzed in this study. Data sharing is not applicable to this article. 
Acknowledgments: The research leading to these results was supported by MICINN with the Ramón\&Cajal grant for M. A. Prieto (RYC-2017-22891) and the Juan de la Cierva_incorporación grant for P. Otero (IJCI-2016-27774); by Xunta de Galicia and University of Vigo supporting the postdoctoral grant of M. Fraga-Corral (ED481B-2019/096) and the pre-doctoral grant for P. García-Oliveira (ED481A-2019/295).

Conflicts of Interest: The authors declare no conflict of interest.

$\begin{array}{ll}\text { Abbreviations } \\ \text { LAB } & \text { Lactic Acid Bacteria } \\ \text { YAN } & \text { Yeast Assimilable Nitrogen } \\ \text { AAB } & \text { Acetic Acid Bacteria } \\ \text { 2PA } & \text { 2-Phenylethyl Acetate } \\ \text { MLF } & \text { Malolactic Fermentation } \\ \text { GC/MS } & \text { Gas Chromatography-Mass Spectrometry } \\ \text { QTL } & \text { Quantitative Trait Loci } \\ \text { HPLC } & \text { High Performance Liquid Chromatography } \\ \text { GMOs } & \text { Genetic Modified Organisms }\end{array}$

\section{References}

1. Pereira, A.G.; Fraga, M.; Garcia-Oliveira, P.; Carpena, M.; Jimenez-Lopez, C.; Lourenço-Lopes, C.; Barros, L.; Ferreira, I.C.F.R.; Prieto, M.A.; Simal-Gandara, J. Management of Wine Aroma Compounds: Principal Basis and Future Perspectives. In WinemakingStabilization, Aging Chemistry and Biochemistry; IntechOpen: London, UK, 2020.

2. Perestrelo, R.; Silva, C.; Gonçalves, C.; Castillo, M.; Câmara, J.S. An Approach of the Madeira Wine Chemistry. Beverages 2020, 6, 12. [CrossRef]

3. Jeromel, A.; Korenika, A.-M.J.; Tomaz, I. 6-An Influence of Different Yeast Species on Wine Aroma Composition. In Fermented Beverages; Grumezescu, A.M., Holban, A.M.B.T.-F.B., Eds.; Woodhead Publishing: Cambridge, UK, 2019; pp. 171-285, ISBN 978-012-815271-3.

4. Ruiz, J.; Kiene, F.; Belda, I.; Fracassetti, D.; Marquina, D.; Navascués, E.; Calderón, F.; Benito, A.; Rauhut, D.; Santos, A.; et al. Effects on varietal aromas during wine making: A review of the impact of varietal aromas on the flavor of wine. Appl. Microbiol. Biotechnol. 2019, 103, 7425-7450. [CrossRef] [PubMed]

5. Styger, G.; Prior, B.; Bauer, F.F. Wine flavor and aroma. J. Ind. Microbiol. Biotechnol. 2011, 38, 1145-1159. [CrossRef] [PubMed]

6. Rapp, A. Volatile flavour of wine: Correlation between instrumental analysis and sensory perception. Food Nahr. 1998, 42, 351-363. [CrossRef]

7. Rapp, A.; Mandery, H. Wine aroma. Experientia 1986, 42, 873-884. [CrossRef]

8. Belda, I.; Ruiz, J.; Esteban-Fernández, A.; Navascués, E.; Marquina, D.; Santos, A.; Moreno-Arribas, M.V. Microbial Contribution to Wine Aroma and Its Intended Use for Wine Quality Improvement. Molecules 2017, 22, 189. [CrossRef]

9. Ribâereau-Gayon, P.; Dubourdieu, D.; Donáeche, B. Handbook of Enology: Volume 1; John Wiley \& Sons: Hoboken, NJ, USA, 2006.

10. Marín-San Román, S.; Rubio-Bretón, P.; Pérez-Álvarez, E.P.; Garde-Cerdán, T. Advancement in analytical techniques for the extraction of grape and wine volatile compounds. Food Res. Int. 2020, 137, 109712. [CrossRef]

11. Blanco-Padilla, A.; Soto, K.M.; Hernández Iturriaga, M.; Mendoza, S. Food antimicrobials nanocarriers. Sci. World J. 2014, 2014, 1-11. [CrossRef]

12. Van Wyk, N.; Grossmann, M.; Wendland, J.; Von Wallbrunn, C.; Pretorius, I.S. The Whiff of Wine Yeast Innovation: Strategies for Enhancing Aroma Production by Yeast during Wine Fermentation. J. Agric. Food Chem. 2019, 67, 13496-13505. [CrossRef]

13. Fariña, L.; Villar, V.; Ares, G.; Carrau, F.; Dellacassa, E.; Boido, E. Volatile composition and aroma profile of Uruguayan Tannat wines. Food Res. Int. 2015, 69, 244-255. [CrossRef]

14. Carpena, M.; Pereira, A.G.; Prieto, M.A.; Simal-Gandara, J. Wine aging technology: Fundamental role of wood barrels. Foods 2020, 9, 1160. [CrossRef] [PubMed]

15. Tao, Y.; García, J.F.; Sun, D.W. Advances in Wine Aging Technologies for Enhancing Wine Quality and Accelerating Wine Aging Process. Crit. Rev. Food Sci. Nutr. 2014, 54, 817-835. [CrossRef] [PubMed]

16. Fraga-Corral, M.; García-Oliveira, P.; Pereira, A.G.; Lourenço-Lopes, C.; Jimenez-Lopez, C.; Prieto, M.A.; Simal-Gandara, J. Technological application of tannin-based extracts. Molecules 2020, 25, 614. [CrossRef] [PubMed]

17. Zohre, D.E.; Erten, H. The influence of Kloeckera apiculata and Candida pulcherrima yeasts on wine fermentation. Process. Biochem. 2002, 38, 319-324. [CrossRef]

18. Tenorio, C.; Gutie, A.R. Analysis of yeast population during spontaneous alcoholic fermentation: Effect of the age of the cellar and the practice of inoculation. Int. J. Food Microbiol. 2005, 103, 49-56. [CrossRef]

19. Padilla, B.; Gil, J.V.; Manzanares, P. Past and future of non-Saccharomyces yeasts: From spoilage microorganisms to biotechnological tools for improving wine aroma complexity. Front. Microbiol. 2016, 7, 411. [CrossRef]

20. Ciani, M.; Comitini, F. Yeast interactions in multi-starter wine fermentation. Curr. Opin. Food Sci. 2015, 1, 1-6. [CrossRef] 
21. Rossouw, D.; Bauer, F.F. Exploring the phenotypic space of non-Saccharomyces wine yeast biodiversity. Food Microbiol. 2016, 55, 32-46. [CrossRef]

22. Canonico, L.; Comitini, F.; Ciani, M. Torulaspora delbrueckii for secondary fermentation in sparkling wine production. Food Microbiol. 2018, 74, 100-106. [CrossRef]

23. Zhang, B.; Xu, D.; Duan, C.; Yan, G. Synergistic effect enhances 2-phenylethyl acetate production in the mixed fermentation of Hanseniaspora vineae and Saccharomyces cerevisiae. Process. Biochem. 2020, 90, 44-49. [CrossRef]

24. Shi, W.K.; Wang, J.; Chen, F.S.; Zhang, X.Y. Effect of Issatchenkia terricola and Pichia kudriavzevii on wine flavor and quality through simultaneous and sequential co-fermentation with Saccharomyces cerevisiae. LWT 2019, 116, 1-9. [CrossRef]

25. Maturano, Y.P.; Mestre, M.V.; Kuchen, B.; Toro, M.E.; Mercado, L.A.; Vazquez, F.; Combina, M. Optimization of fermentationrelevant factors: A strategy to reduce ethanol in red wine by sequential culture of native yeasts. Int. J. Food Microbiol. 2019, 289, 40-48. [CrossRef] [PubMed]

26. Renault, P.; Coulon, J.; de Revel, G.; Barbe, J.C.; Bely, M. Increase of fruity aroma during mixed T. delbrueckii/S. cerevisiae wine fermentation is linked to specific esters enhancement. Int. J. Food Microbiol. 2015, 207, 40-48. [CrossRef] [PubMed]

27. Mina, M.; Tsaltas, D. Contribution of Yeast in Wine Aroma and Flavour. In Yeast-Industrial Applications; IntechOpen: London, UK, 2017; pp. 117-134.

28. Marsit, S.; Dequin, S. Diversity and adaptive evolution of Saccharomyces wine yeast: A review. FEMS Yeast Res. 2015, 15, 1-12. [CrossRef]

29. Longin, C.; Petitgonnet, C.; Guilloux-Benatier, M.; Rousseaux, S.; Alexandre, H. Application of flow cytometry to wine microorganisms. Food Microbiol. 2017, 62, 221-231. [CrossRef]

30. National Center for Biotechnology NCBI Taxonomy Browser. Available online: https://www.ncbi.nlm.nih.gov/Taxonomy/ Browser/wwwtax.cgi (accessed on 15 November 2020).

31. Schreier, P.; Jennings, W.G. Flavor composition of wines: A review. Crit. Rev. Food Sci. Nutr. 1979, 12, 59-111. [CrossRef]

32. Louw, L.; Tredoux, A.G.J.; Van Rensburg, P.; Kidd, M.; Naes, T.; Nieuwoudt, H.H. Fermentation-derived aroma compounds in varietal young wines from South Africa. S. Afr. J. Enol. Vitic. 2010, 31, 213-225. [CrossRef]

33. Muñoz, D.; Peinado, R.A.; Medina, M.; Moreno, J. Higher alcohols concentration and its relation with the biological aging evolution. Eur. Food Res. Technol. 2006, 222, 629-635. [CrossRef]

34. Tokpohozin, S.E.; Fischer, S.; Becker, T. Selection of a new Saccharomyces yeast to enhance relevant sorghum beer aroma components, higher alcohols and esters. Food Microbiol. 2019, 83, 181-186. [CrossRef]

35. Stribny, J.; Gamero, A.; Pérez-Torrado, R.; Querol, A. Saccharomyces kudriavzevii and Saccharomyces uvarum differ from Saccharomyces cerevisiae during the production of aroma-active higher alcohols and acetate esters using their amino acidic precursors. Int. J. Food Microbiol. 2015, 205, 41-46. [CrossRef]

36. Canonico, L.; Solomon, M.; Comitini, F.; Ciani, M.; Varela, C. Volatile profile of reduced alcohol wines fermented with selected non-Saccharomyces yeasts under different aeration conditions. Food Microbiol. 2019, 84, 103247. [CrossRef] [PubMed]

37. Pretorius, I.S.; Curtin, C.D.; Chambers, P.J. Designing wine yeast for the future. In Advances in Fermented Foods and Beverages: Improving Quality, Technologies and Health Benefits; Woodhead Publishing: Cambridge, UK, 2015; pp. 197-226, ISBN 9781782420248.

38. Jouhten, P.; Ponomarova, O.; Gonzalez, R.; Patil, K.R. Saccharomyces cerevisiae metabolism in ecological context. FEMS Yeast Res. 2016, 16, 1-8. [CrossRef] [PubMed]

39. Jagtap, U.B.; Jadhav, J.P.; Bapat, V.A.; Pretorius, I.S. Synthetic biology stretching the realms of possibility in wine yeast research. Int. J. Food Microbiol. 2017, 252, 24-34. [CrossRef] [PubMed]

40. Goddard, M.R.; Greig, D. Saccharomyces cerevisiae: A nomadic yeast with no niche? FEMS Yeast Res. 2015, 15, 1-6. [CrossRef]

41. Suárez-Lepe, J.A.; Morata, A. New trends in yeast selection for winemaking. Trends Food Sci. Technol. 2012, 23, 39-50. [CrossRef]

42. Capozzi, V.; Garofalo, C.; Chiriatti, M.A.; Grieco, F.; Spano, G. Microbial terroir and food innovation: The case of yeast biodiversity in wine. Microbiol. Res. 2015, 181, 75-83. [CrossRef]

43. Hirst, M.B.; Richter, C.L. Review of aroma formation through metabolic pathways of Saccharomyces cerevisiae in beverage fermentations. Am. J. Enol. Vitic. 2016, 67, 361-370. [CrossRef]

44. Di Gianvito, P.; Perpetuini, G.; Tittarelli, F.; Schirone, M.; Arfelli, G.; Piva, A.; Patrignani, F.; Lanciotti, R.; Olivastri, L.; Suzzi, G.; et al. Impact of Saccharomyces cerevisiae strains on traditional sparkling wines production. Food Res. Int. 2018, 109, 552-560. [CrossRef]

45. Capece, A.; Granchi, L.; Guerrini, S.; Mangani, S.; Romaniello, R.; Vincenzini, M.; Romano, P. Diversity of Saccharomyces cerevisiae strains isolated from two Italian wine-producing regions. Front. Microbiol. 2016, 7, 1-11. [CrossRef]

46. Comitini, F.; Capece, A.; Ciani, M.; Romano, P. New insights on the use of wine yeasts. Curr. Opin. Food Sci. 2017, 13, 44-49. [CrossRef]

47. Knight, S.; Klaere, S.; Fedrizzi, B.; Goddard, M.R. Regional microbial signatures positively correlate with differential wine phenotypes: Evidence for a microbial aspect to terroir. Sci. Rep. 2015, 5, 1-10. [CrossRef] [PubMed]

48. Rollero, S.; Bloem, A.; Camarasa, C.; Sanchez, I.; Ortiz-Julien, A.; Sablayrolles, J.M.; Dequin, S.; Mouret, J.R. Combined effects of nutrients and temperature on the production of fermentative aromas by Saccharomyces cerevisiae during wine fermentation. Appl. Microbiol. Biotechnol. 2015, 99, 2291-2304. [CrossRef] [PubMed]

49. Gonzalez, R.; Morales, P. Wine secondary aroma: Understanding yeast production of higher alcohols. Microb. Biotechnol. 2017, 10, 1449-1450. [CrossRef] [PubMed] 
50. Martin, V.; Valera, M.J.; Medina, K.; Boido, E.; Carrau, F. Oenological Impact of the Hanseniaspora/Kloeckera Yeast Genus on Wines-A Review. Fermentation 2018, 4, 76. [CrossRef]

51. Jolly, N.P.; Varela, C.; Pretorius, I.S. Not your ordinary yeast: Non-Saccharomyces yeasts in wine production uncovered. FEMS Yeast Res. 2014, 14, 215-237. [CrossRef] [PubMed]

52. Hu, L.; Wang, J.; Ji, X.; Liu, R.; Chen, F. Selection of non-Saccharomyces yeasts for orange wine fermentation based on their enological traits and volatile compounds formation. J. Food Sci. Technol. 2018, 55, 4001-4012. [CrossRef] [PubMed]

53. Rojas, V.; Manzanares, P.; Gil, V.; Pinaga, F. Studies on acetate ester production by non-Saccharomyces wine yeasts. Int. J. Food Microbiol. 2001, 70, 283-289. [CrossRef]

54. Carrau, F. Native yeasts for low input winemaking: Searching for wine diversity and increased complexity. In Advances in Applied Microbiology V. 111; Academic Press: Cambridge, MA, USA, 2006; pp. 33-39.

55. Benito, Á.; Calder, F.; Benito, S. The Influence of Non-Saccharomyces Species on Wine Fermentation Quality Parameters. Fermentation 2019, 5, 54. [CrossRef]

56. Martin, V.; Giorello, F.; Farin, L.; Minteguiaga, M.; Salzman, V.; Boido, E.; Aguilar, P.S.; Gaggero, C.; Dellacassa, E.; Mas, A.; et al. De Novo Synthesis of Benzenoid Compounds by the Yeast Hanseniaspora vineae Increases the Flavor Diversity of Wines. J. Agric. Food Chem. 2016, 64, 4574-4583. [CrossRef]

57. Martin, V.; Boido, E.; Giorello, F.; Mas, A.; Dellacassa, E.; Carrau, F. Effect of yeast assimilable nitrogen on the synthesis of phenolic aroma compounds by Hanseniaspora vineae strains. Yeast 2016, 33, 323-328. [CrossRef]

58. Moreira, N.; Mendes, F.; de Guedes Pinho, P.; Hogg, T.; Vasconcelos, I. Heavy sulphur compounds, higher alcohols and esters production profile of Hanseniaspora uvarum and Hanseniaspora guilliermondii grown as pure and mixed cultures in grape must. Int. J. Food Microbiol. 2008, 124, 231-238. [CrossRef] [PubMed]

59. Viana, F.; Gil, J.V.; Vallés, S.; Manzanares, P. Increasing the levels of 2-phenylethyl acetate in wine through the use of a mixed culture of Hanseniaspora osmophila and Saccharomyces cerevisiae. Int. J. Food Microbiol. 2009, 135, 68-74. [CrossRef] [PubMed]

60. Barbosa, C.; Mendes-Faia, A.; Lage, P.; Mira, N.P.; Mendes-Ferreira, A. Genomic expression program of Saccharomyces cerevisiae along a mixed-culture wine fermentation with Hanseniaspora guilliermondii. Microb. Cell Fact. 2015, 14, 1-17. [CrossRef] [PubMed]

61. Luan, Y.; Zhang, B.Q.; Duan, C.Q.; Yan, G.L. Effects of different pre-fermentation cold maceration time on aroma compounds of Saccharomyces cerevisiae co-fermentation with Hanseniaspora opuntiae or Pichia kudriavzevii. LWT Food Sci. Technol. 2018, 92, 177-186. [CrossRef]

62. Hu, K.; Jin, G.J.; Xu, Y.H.; Tao, Y.S. Wine aroma response to different participation of selected Hanseniaspora uvarum in mixed fermentation with Saccharomyces cerevisiae. Food Res. Int. 2018, 108, 119-127. [CrossRef]

63. Hu, K.; Jin, G.J.; Mei, W.C.; Li, T.; Tao, Y.S. Increase of medium-chain fatty acid ethyl ester content in mixed H. uvarum/S. cerevisiae fermentation leads to wine fruity aroma enhancement. Food Chem. 2018, 239, 495-501. [CrossRef]

64. De Benedictis, M.; Bleve, G.; Tristezza, M.; Tufariello, M.; Grieco, F. An optimized procedure for the enological selection of non-Saccharomyces starter cultures. Antonie van Leeuwenhoek. Int. J. Gen. Mol. Microbiol. 2011, 99, 189-200. [CrossRef]

65. Medina, K.; Boido, E.; Fariña, L.; Gioia, O.; Gomez, M.E.; Barquet, M.; Gaggero, C.; Dellacassa, E.; Carrau, F. Increased flavour diversity of Chardonnay wines by spontaneous fermentation and co-fermentation with Hanseniaspora vineae. Food Chem. 2013, 141, 2513-2521. [CrossRef]

66. Lleixà, J.; Martín, V.; del Portillo, M.C.; Carrau, F.; Beltran, G.; Mas, A. Comparison of fermentation and wines produced by inoculation of Hanseniaspora vineae and Saccharomyces cerevisiae. Front. Microbiol. 2016, 7, 1-12. [CrossRef]

67. Englezos, V.; Torchio, F.; Cravero, F.; Marengo, F.; Giacosa, S.; Gerbi, V.; Rantsiou, K.; Rolle, L.; Cocolin, L. Aroma profile and composition of Barbera wines obtained by mixed fermentations of Starmerella bacillaris (synonym Candida zemplinina) and Saccharomyces cerevisiae. LWT Food Sci. Technol. 2016, 73, 567-575. [CrossRef]

68. González-Royo, E.; Pascual, O.; Kontoudakis, N.; Esteruelas, M.; Esteve-Zarzoso, B.; Mas, A.; Canals, J.M.; Zamora, F. Oenological consequences of sequential inoculation with non-Saccharomyces yeasts (Torulaspora delbrueckii or Metschnikowia pulcherrima) and Saccharomyces cerevisiae in base wine for sparkling wine production. Eur. Food Res. Technol. 2015, 240, 999-1012. [CrossRef]

69. Calabretti, A.; La Cara, F.; Sorrentino, A.; Di Stasio, M.; Santomauro, F.; Rastrelli, L.; Gabrielli, L.; Limone, F.; Volpe, M.G. Characterization of volatile fraction of typical Irpinian wines fermented with a new starter yeast. World J. Microbiol. Biotechnol. 2012, 28, 1433-1442. [CrossRef] [PubMed]

70. Hu, K.; Zhu, X.L.; Mu, H.; Ma, Y.; Ullah, N.; Tao, Y.S. A novel extracellular glycosidase activity from Rhodotorula mucilaginosa: Its application potential in wine aroma enhancement. Lett. Appl. Microbiol. 2016, 62, 169-176. [CrossRef] [PubMed]

71. Wang, X.C.; Li, A.H.; Dizy, M.; Ullah, N.; Sun, W.X.; Tao, Y.S. Evaluation of aroma enhancement for "Ecolly" dry white wines by mixed inoculation of selected Rhodotorula mucilaginosa and Saccharomyces cerevisiae. Food Chem. 2017, 228, 550-559. [CrossRef] [PubMed]

72. Martínez-garcía, R.; García-martínez, T.; Puig-pujol, A.; Carlos, J.; Moreno, J. Changes in sparkling wine aroma during the second fermentation under CO2 pressure in sealed bottle. Food Chem. 2017, 237, 1030-1040. [CrossRef]

73. Loira, I.; Morata, A.; Comuzzo, P.; Callejo, M.J.; González, C.; Calderón, F.; Suárez-Lepe, J.A. Use of Schizosaccharomyces pombe and Torulaspora delbrueckii strains in mixed and sequential fermentations to improve red wine sensory quality. Food Res. Int. 2015, 76, 325-333. [CrossRef] 
74. Renault, P.; Coulon, J.; Moine, V.; Thibon, C.; Bely, M. Enhanced 3-sulfanylhexan-1-ol production in sequential mixed fermentation with Torulaspora delbrueckii/Saccharomyces cerevisiae reveals a situation of synergistic interaction between two industrial strains. Front. Microbiol. 2016, 7, 293. [CrossRef]

75. Egue, L.A.N.; Bouatenin, J.K.M.; Florent, K.N.; Koussemon-camara, M. Microbial Pathogenesis Virulence factors and determination of antifungal susceptibilities of Candida species isolated from palm wine and sorghum beer. Microb. Pthogenes 2018, 124, 5-10. [CrossRef]

76. Morrison-whittle, P.; Lee, S.A.; Fedrizzi, B.; Goddard, M.R. Co-evolution as Tool for Diversifying Flavor and Aroma Profiles of Wines. Front. Microbiol. 2018, 9, 1-10. [CrossRef]

77. Soden, A.; Francis, I.L.; Oakey, H.; Henschke, P.A. Effects of co-fermentation with Candida stellata and Saccharomyces cerevisiae on the aroma and composition of Chardonnay wine. Aust. J. Grape Wine Res. 2000, 6, 21-30. [CrossRef]

78. Rocha, M.; Rodrigues, F.; Coutinho, P.; Delgadillo, I.; Coimbra, M.A. Volatile composition of Baga red wine Assessment of the identification of the would-be impact odourants. Anal. Chim. Acta 2004, 513, 257-262. [CrossRef]

79. Varela, C.; Barker, A.; Tran, T.; Borneman, A.; Curtin, C. Sensory profile and volatile aroma composition of reduced alcohol Merlot wines fermented with Metschnikowia pulcherrima and Saccharomyces uvarum. Int. J. Food Microbiol. 2017, 252, 1-9. [CrossRef] [PubMed]

80. Hranilovic, A.; Gambetta, J.M.; Jeffery, D.W.; Grbin, P.R.; Jiranek, V. Lower-alcohol wines produced by Metschnikowia pulcherrima and Saccharomyces cerevisiae co-fermentations: The effect of sequential inoculation timing. Int. J. Food Microbiol. 2020, 329, 108651. [CrossRef] [PubMed]

81. Escribano, R.; González-Arenzana, L.; Portu, J.; Garijo, P.; López-Alfaro, I.; López, R.; Santamaría, P.; Gutiérrez, A.R. Wine aromatic compound production and fermentative behaviour within different non-Saccharomyces species and clones. J. Appl. Microbiol. 2018, 124, 1521-1531. [CrossRef]

82. Manzanares, P. Past and Future of Non-Saccharomyces Yeasts: From Spoilage Microorganisms to Biotechnological Tools for Improving Wine Aroma Past and Future of Non-Saccharomyces Yeasts: From Spoilage Microorganisms to Biotechnological Tools for Improving Wine Aroma Co. Front. Microbiol. 2016. [CrossRef]

83. Otero, R.R.C.; Pe, A.I.B. Optimization of a rapid method for studying the cellular location of $\mathrm{b}$-glucosidase activity in wine yeasts. J. Appl. Microbiol. 2005, 558-564. [CrossRef]

84. Prior, K.J.; Bauer, F.F.; Divol, B. The utilisation of nitrogenous compounds by commercial non-Saccharomyces yeasts associated with wine. J. Food Microbiol. 2019, 79, 75-84. [CrossRef]

85. Renault, P.; Miot-Sertier, C.; Marullo, P.; Hernández-Orte, P.; Lagarrigue, L.; Lonvaud-Funel, A.; Bely, M. Genetic characterization and phenotypic variability in Torulaspora delbrueckii species: Potential applications in the wine industry. Int. J. Food Microbiol. 2009, 134, 201-210. [CrossRef]

86. Ferrando, N.; Araque, I.; Ortís, A.; Thornes, G.; Bautista-Gallego, J.; Bordons, A.; Reguant, C. Evaluating the effect of using non-Saccharomyces on Oenococcus oeni and wine malolactic fermentation. Food Res. Int. 2020, 138, 1-9. [CrossRef]

87. Lonvaud-Funel, A. Lactic Acid Bacteria and Malolactic Fermentation in Wine. In Biotechnology of Lactic Acid Bacteria: Novel Applications, 2nd ed.; Wiley: Hoboken, NJ, USA, 2015; pp. 231-247.

88. Cappello, M.S.; Zapparoli, G.; Logrieco, A.; Bartowsky, E.J. Linking wine lactic acid bacteria diversity with wine aroma and flavour. Int. J. Food Microbiol. 2017, 243, 16-27. [CrossRef]

89. Dicks, L.M.T.; Dellaglio, F.; Collins, M.D. Proposal to reclassify Leuconostoc oenos as Oenococcus oeni [corrig.] gen. nov., comb. nov. Int. J. Syst. Bacteriol. 1995, 45, 395-397. [CrossRef] [PubMed]

90. Diez-Ozaeta, I.; Lavilla, M.; Amárita, F. Technological characterisation of potential malolactic starters from Rioja Alavesa winemaking region. LWT 2020, 134, 1-8. [CrossRef]

91. Badotti, F.; Moreira, A.P.B.; Tonon, L.A.C.; de Lucena, B.T.L.; de Gomes, F.C.O.; Kruger, R.; Thompson, C.C.; de Morais, M.A.; Rosa, C.A.; Thompson, F.L. Oenococcus alcoholitolerans sp. nov., a lactic acid bacteria isolated from cachaça and ethanol fermentation processes. Antonie van Leeuwenhoek. Int. J. Gen. Mol. Microbiol. 2014, 106, 1259-1267. [CrossRef]

92. Endo, A.; Okada, S. Oenococcus kitaharae sp. nov., a non-acidophilic and non-malolactic-fermenting oenococcus isolated from a composting distilled shochu residue. Int. J. Syst. Evol. Microbiol. 2006, 56, 2345-2348. [CrossRef] [PubMed]

93. Pripis-Nicolau, L.; De Revel, G.; Bertrand, A.; Lonvaud-Funel, A. Methionine catabolism and production of volatile sulphur compounds by Oenococcus œni. J. Appl. Microbiol. 2004, 96, 1176-1184. [CrossRef]

94. Lombardi, S.J.; Pannella, G.; Iorizzo, M.; Testa, B.; Succi, M.; Tremonte, P.; Sorrentino, E.; Di Renzo, M.; Strollo, D.; Coppola, R. Inoculum strategies and performances of malolactic starter lactobacillus plantarum M10: Impact on chemical and sensorial characteristics of fiano wine. Microorganisms 2020, 8, 516. [CrossRef]

95. Iorizzo, M.; Testa, B.; Lombardi, S.J.; García-Ruiz, A.; Muñoz-González, C.; Bartolomé, B.; Moreno-Arribas, M.V. Selection and technological potential of Lactobacillus plantarum bacteria suitable for wine malolactic fermentation and grape aroma release. LWT Food Sci. Technol. 2016, 73, 557-566. [CrossRef]

96. Hernandez-Orte, P.; Cersosimo, M.; Loscos, N.; Cacho, J.; Garcia-Moruno, E.; Ferreira, V. Aroma development from non-floral grape precursors by wine lactic acid bacteria. Food Res. Int. 2009, 42, 773-781. [CrossRef]

97. Devi, A.; Anu-Appaiah, K.A. Mixed malolactic co-culture (Lactobacillus plantarum and Oenococcus oeni) with compatible Saccharomyces influences the polyphenolic, volatile and sensory profile of Shiraz wine. LWT 2021, 135, 110246. [CrossRef] 
98. Costello, P.J.; Siebert, T.E.; Solomon, M.R.; Bartowsky, E.J. Synthesis of fruity ethyl esters by acyl coenzyme A: Alcohol acyltransferase and reverse esterase activities in Oenococcus oeni and Lactobacillus plantarum. J. Appl. Microbiol. 2013, 114, 797-806. [CrossRef]

99. Knoll, C.; Fritsch, S.; Schnell, S.; Grossmann, M.; Rauhut, D.; Du Toit, M. Influence of pH and ethanol on malolactic fermentation and volatile aroma compound composition in white wines. LWT Food Sci. Technol. 2011, 44, 2077-2086. [CrossRef]

100. Lytra, G.; Miot-Sertier, C.; Moine, V.; Coulon, J.; Barbe, J.C. Influence of must yeast-assimilable nitrogen content on fruity aroma variation during malolactic fermentation in red wine. Food Res. Int. 2020, 135, 1-11. [CrossRef] [PubMed]

101. Liu, W.; Li, H.; Jiang, D.; Zhang, Y.; Zhang, S.; Sun, S. Effect of Saccharomyces cerevisiae, Torulaspora delbrueckii and malolactic fermentation on fermentation kinetics and sensory property of black raspberry wines. Food Microbiol. 2020, 91, 1-9. [CrossRef] [PubMed]

102. Zhao, C.; Su, W.; Mu, Y.; Jiang, L.; Mu, Y. Correlations between microbiota with physicochemical properties and volatile flavor components in black glutinous rice wine fermentation. Food Res. Int. 2020, 138, 109800. [CrossRef] [PubMed]

103. Antalick, G.; Perello, M.C.; De Revel, G. Characterization of fruity aroma modifications in red wines during malolactic fermentation. J. Agric. Food Chem. 2012, 60, 12371-12383. [CrossRef] [PubMed]

104. Guo, L.; Luo, Y.; Zhou, Y.; Bianba, C.; Guo, H.; Zhao, Y.; Fu, H. Exploring microbial dynamics associated with flavours production during highland barley wine fermentation. Food Res. Int. 2020, 130, 108971. [CrossRef]

105. Roda, A.; Lucini, L.; Torchio, F.; Dordoni, R.; De Faveri, D.M.; Lambri, M. Metabolite profiling and volatiles of pineapple wine and vinegar obtained from pineapple waste. Food Chem. 2017, 229, 734-742. [CrossRef]

106. Jiang, L.; Su, W.; Mu, Y.; Mu, Y. Major Metabolites and Microbial Community of Fermented Black Glutinous Rice Wine with Different Starters. Front. Microbiol. 2020, 11, 1-13. [CrossRef]

107. Gil-Sánchez, I.; Bartolomé Suáldea, B.; Victoria Moreno-Arribas, M. Malolactic Fermentation. In Red Wine Technology; Morata, A., Ed.; Academic Press: Cambridge, MA, USA, 2018; pp. 85-98, ISBN 9780128144008.

108. Brizuela, N.S.; Bravo-Ferrada, B.M.; La Hens, D.V.; Hollmann, A.; Delfederico, L.; Caballero, A.; Tymczyszyn, E.E.; Semorile, L. Comparative vinification assays with selected Patagonian strains of Oenococcus oeni and Lactobacillus plantarum. LWT Food Sci. Technol. 2017, 77, 348-355. [CrossRef]

109. Brizuela, N.; Tymczyszyn, E.E.; Semorile, L.C.; Valdes La Hens, D.; Delfederico, L.; Hollmann, A.; Bravo-Ferrada, B. Lactobacillus plantarum as a malolactic starter culture in winemaking: A new (old) player? Electron. J. Biotechnol. 2019, 38, 10-18. [CrossRef]

110. Balmaseda, A.; Rozès, N.; Leal, M.Á.; Bordons, A.; Reguant, C. Impact of changes in wine composition produced by nonSaccharomyces on malolactic fermentation. Int. J. Food Microbiol. 2021, 337, 108954. [CrossRef] [PubMed]

111. Strickland, M.T.; Schopp, L.M.; Edwards, C.G.; Osborne, J.P. Impact of Pediococcus spp. on pinot noir wine quality and growth of Brettanomyces. Am. J. Enol. Vitic. 2016, 67, 188-198. [CrossRef]

112. Kaur, B.; Kumar, B.; Kaur, G.; Chakraborty, D.; Kaur, K. Application of recombinant Pediococcus acidilactici BD16 (fcs+/ech+) in malolactic fermentation. Appl. Microbiol. Biotechnol. 2015, 99, 3015-3028. [CrossRef] [PubMed]

113. Matei, F.; Kosseva, M.R. Microbiology of Fruit Wine Production. In Science and Technology of Fruit Wine Production; Elsevier Inc.: Amsterdam, The Netherlands, 2017; pp. 73-103, ISBN 9780128010341.

114. Rollán, G.C.; Farías, M.E.; De Nadra, M.C.M. Characterization of two extracellular proteases from Leuconostoc oenos. World J. Microbiol. Biotechnol. 1995, 11, 153-155. [CrossRef]

115. Bekal, S.; Van Beeumen, J.; Samyn, B.; Garmyn, D.; Henini, S.; Diviès, C.; Prévost, H. Purification of Leuconostoc mesenteroides citrate lyase and cloning and characterization of the citCDEFG gene cluster. J. Bacteriol. 1998, 180, 647-654. [CrossRef]

116. Mateo, E.; Torija, M.J.; Mas, A.; Bartowsky, E.J. Acetic acid bacteria isolated from grapes of South Australian vineyards. Int. J. Food Microbiol. 2014, 178, 98-106. [CrossRef]

117. Bartowsky, E.J.; Xia, D.; Gibson, R.L.; Fleet, G.H.; Henschke, P.A. Spoilage of bottled red wine by acetic acid bacteria. Lett. Appl. Microbiol. 2003. [CrossRef]

118. Nurgel, C.; Pickering, G.J.; Inglis, D.L. Sensory and chemical characteristics of Canadian ice wines. J. Sci. Food Agric. 2004, 84, 1675-1684. [CrossRef]

119. Bartowsky, E.J.; Henschke, P.A. Acetic acid bacteria spoilage of bottled red wine-A review. Int. J. Food Microbiol. 2008, 125, 60-70. [CrossRef]

120. Valera, M.J.; Torija, M.J.; Mas, A.; Mateo, E. Acetobacter malorum and Acetobacter cerevisiae identification and quantification by Real-Time PCR with TaqMan-MGB probes. Food Microbiol. 2013, 36, 30-39. [CrossRef]

121. Valera, M.J.; Laich, F.; González, S.S.; Torija, M.J.; Mateo, E.; Mas, A. Diversity of acetic acid bacteria present in healthy grapes from the Canary Islands. Int. J. Food Microbiol. 2011, 151, 105-112. [CrossRef] [PubMed]

122. Shamala, T.R.; Sreekantiah, K.R. Microbiological and biochemical studies on traditional Indian palm wine fermentation. Food Microbiol. 1988, 5, 157-162. [CrossRef]

123. Hommel, R.K. Gluconobacter. In Encyclopedia of Food Microbiology, 2nd ed.; Academic Press: Amsterdam, The Netherlands, 2014; Volume 2, pp. 99-105, ISBN 9780123847331.

124. Amaresan, N.; Annapurna, K.; Sankaranarayanan, A.M.; Senthil Kumar, K.K. (Eds.) Mitesh Dwivedi Gluconobacter. In Beneficial Microbes in Agro-Ecology; Academic Press: Cambridge, MA, USA, 2020; pp. 521-544, ISBN 978-0-12-823414-3.

125. Hyma, K.E.; Saerens, S.M.; Verstrepen, K.J.; Fay, J.C. Divergence in wine characteristics produced by wild and domesticated strains of Saccharomyces cerevisiae. FEMS Yeast Res. 2011, 11, 540-551. [CrossRef] [PubMed] 
126. Belda, I.; Gobbi, A.; Ruiz, J.; de Celis, M.; Ortiz-Álvarez, R.; Acedo, A.; Santos, A. Microbiomics to Define Wine Terroir. In Comprehensive Foodomics; Cifuentes, A., Ed.; Elsevier: Amsterdam, The Netherlands, 2021; pp. 438-451, ISBN 978-0-12-816396-2.

127. Tilloy, V.; Cadière, A.; Ehsani, M.; Dequin, S. Reducing alcohol levels in wines through rational and evolutionary engineering of Saccharomyces cerevisiae. Int. J. Food Microbiol. 2015, 213, 49-58. [CrossRef] [PubMed]

128. Salinas, F.; Cubillos, F.A.; Soto, D.; Garcia, V.; Bergström, A.; Warringer, J.; Ganga, M.A.; Louis, E.J.; Liti, G.; Martinez, C. The Genetic Basis of Natural Variation in Oenological Traits in Saccharomyces cerevisiae. PLoS ONE 2012, 7, e49640. [CrossRef]

129. Pérez-Torrado, R.; Querol, A.; Guillamón, J.M. Genetic improvement of non-GMO wine yeasts: Strategies, advantages and safety. Trends Food Sci. Technol. 2015, 45, 1-11. [CrossRef]

130. Yang, X.; Guo, Y.; Zhu, J.; Niu, Z.; Shi, G.; Liu, Z.; Li, K.; Guo, X. Genetic diversity and association study of aromatics in grapevine. J. Am. Soc. Hortic. Sci. 2017, 142, 225-231. [CrossRef]

131. Mendes, I.; Sanchez, I.; Franco-Duarte, R.; Camarasa, C.; Schuller, D.; Dequin, S.; Sousa, M.J. Integrating transcriptomics and metabolomics for the analysis of the aroma profiles of Saccharomyces cerevisiae strains from diverse origins. BMC Genom. 2017, 18, 1-13. [CrossRef]

132. Barbosa, C.; García-Martínez, J.; Pérez-Ortín, J.E.; Mendes-Ferreira, A. Comparative transcriptomic analysis reveals similarities and dissimilarities in Saccharomyces cerevisiae wine strains response to nitrogen availability. PLoS ONE 2015, 10, e0122709. [CrossRef]

133. Liu, P.; Wang, Y.; Ye, D.; Duan, L.; Duan, C.; Yan, G. Effect of the addition of branched-chain amino acids to non-limited nitrogen synthetic grape must on volatile compounds and global gene expression during alcoholic fermentation. Aust. J. Grape Wine Res. 2018, 24, 197-205. [CrossRef]

134. Katarína, F.; Katarína, M.; Katarína, Ď.; Ivan, Š.; Fedor, M. Influence of yeast strain on aromatic profile of Gewürztraminer wine. LWT Food Sci. Technol. 2014, 59, 256-262. [CrossRef]

135. Tronchoni, J.; Curiel, J.A.; Morales, P.; Torres-Pérez, R.; Gonzalez, R. Early transcriptional response to biotic stress in mixed starter fermentations involving Saccharomyces cerevisiae and Torulaspora delbrueckii. Int. J. Food Microbiol. 2017, 241, 60-68. [CrossRef] [PubMed]

136. Tondini, F.; Lang, T.; Chen, L.; Herderich, M.; Jiranek, V. Linking gene expression and oenological traits: Comparison between Torulaspora delbrueckii and Saccharomyces cerevisiae strains. Int. J. Food Microbiol. 2019, 294, 42-49. [CrossRef] [PubMed]

137. Ruiz, J.; de Celis, M.; de Toro, M.; Mendes-Ferreira, A.; Rauhut, D.; Santos, A.; Belda, I. Phenotypic and transcriptional analysis of Saccharomyces cerevisiae during wine fermentation in response to nitrogen nutrition and co-inoculation with Torulaspora delbrueckii. Food Res. Int. 2020, 137, 1-12. [CrossRef] [PubMed]

138. Lin, J.; Massonnet, M.; Cantu, D. The genetic basis of grape and wine aroma. Hortic. Res. 2019, 6, 1-24. [CrossRef] [PubMed]

139. Moreno-Arribas, M.V.; Polo, M.C. Winemaking biochemistry and microbiology: Current knowledge and future trends. Crit. Rev. Food Sci. Nutr. 2005, 45, 265-286. [CrossRef]

140. Schmidtke, L.M.; Blackman, J.W.; Agboola, S.O. Production technologies for reduced alcoholic wines. J. Food Sci. $2012,77$. [CrossRef]

141. Ozturk, B.; Anli, E. Different techniques for reducing alcohol levels in wine: A review. BIO Web Conf. 2014, 3, 02012. [CrossRef]

142. Petruzzi, L.; Capozzi, V.; Berbegal, C.; Corbo, M.R.; Bevilacqua, A.; Spano, G.; Sinigaglia, M. Microbial resources and enological significance: Opportunities and benefits. Front. Microbiol. 2017, 8, 1-13. [CrossRef]

143. Bordiga, M.; Rinaldi, M.; Locatelli, M.; Piana, G.; Travaglia, F.; Coïsson, J.D.; Arlorio, M. Characterization of Muscat wines aroma evolution using comprehensive gas chromatography followed by a post-analytic approach to 2D contour plots comparison. Food Chem. 2013, 140, 57-67. [CrossRef] 